University of Zurich

Department of Economics

Working Paper Series

ISSN 1664-7041 (print)

ISSN 1664-705X (online)

Working Paper No. 81

\title{
Trade and Growth in an Unequal Global Economy
}

Andreas Kohler

June 2012 


\title{
TRADE AND GROWTH IN AN
}

\section{Unequal Global ECONOMY*}

\author{
Andreas Kohler ${ }^{\dagger}$
}

June 4, 2012

\begin{abstract}
This paper studies the patterns of trade and the incentives to innovate in an unequal global economy. We introduce non-homothetic preferences in a general-equilibrium model of endogenous growth and international trade between two countries, and argue that the effects of market integration on the consequent trade patterns and the incentives to innovate depend on the degree of income inequality across countries. We find that if inequality across countries is low, the extensive margin of trade between countries is high whereas the world growth rate is low. The introduction of non-homothetic preferences rises a number of interesting questions that are not an issue in the standard model. For example, we discuss the design of intellectual property rights, in particular national vs. international exhaustion of patents, and argue that households in poor and rich countries might not see eye to eye depending on how poor households weigh future losses in consumption against present gains. Furthermore, we address the welfare consequences of a trade liberalization, and show that households in the poor country might loose relative to households in the rich country if trade costs fall from a high to a sufficiently low level.
\end{abstract}

JEL classification: D30, O30, F10

Keywords: Growth, Inequality, International trade

${ }^{*}$ I thank Josef Zweimüller, Reto Foellmi, Claudia Bernasconi and Christian Hepenstrick for valuable discussions. Financial support by the Swiss National Science Foundation (SNF) is gratefully acknowledged.

${ }^{\dagger}$ University of Zurich, Department of Economics, Muehlebachstrasse 86, CH-8008 Zürich, email: andreas.kohler@econ.uzh.ch 


\section{Introduction}

We observe vast differences in per capita incomes across countries and regions in the world. For example, GDP per capita ${ }^{1}$ in the United States was about 6 times as high in 2009 as GDP per capita in China. Even average GDP per capita across all OECD countries was about 3 times as high in 2009 as average GDP per capita across all non-OECD countries. Instead of analyzing the sources of theses differences in per capita incomes across countries, an undoubtedly interesting and challenging question, this paper looks at the other side of the same coin, by providing a theoretical framework that allows us to analyze the consequences of differences in per capita incomes across countries or regions, taking these differences as given, for the patterns of international trade, as well as the incentives to innovate in the world economy.

To this end, we extend Grossman and Helpman's (1991) seminal analysis of trade and growth in a global economy by addressing the effects of income inequality across countries on international trade and innovation. Our contribution to the literature is to introduce non-homothetic preferences in Grossman and Helpman's (1991) general-equilibrium model of horizontal endogenous innovation and costly international trade between two countries (in particular, see their Chapter 9 on "Trade and Growth"). This allows us to study the channels through which the structure of the demand side affects the incentives to innovate in an international economy, and at the same time, determines the patterns of trade between countries. In the standard model with homothetic preferences inequality in per capita incomes across countries has no effect on the incentives to innovate or the patterns of international trade. The reason is that with homothetic preferences only total lifetime income in the world economy matters for innovation and trade but not the distribution of income across countries. However, with non-homothetic preferences the distribution of income across countries has important implications for the incentives to innovate and the patterns of international trade. We show that in the presence of transportation costs arbitrage opportunities emerge if the level of inequality across countries is relatively high. This threat of parallel imports induces some firms located in the rich country, i.e the country with the relatively high per capita income, to forgo a larger market (market size effect) in order to be able to charge higher prices (price effect). Since households in the poor country cannot afford to consume all goods produced in the rich country less resources in the rich country have to be allocated to the production sector to satisfy the needs of households in the poor country. Hence, more resources can be allocated to the research and development sector of the economy, which allows the (world) economy to grow at a higher rate. An equivalent argument is that when incomes are concentrated in one country,

\footnotetext{
${ }^{1} \mathrm{PPP}$ at 2005 constant prices, source PWT 7.0.
} 
the markups firms can charge are high, and therefore the incentives to innovate are high. In contrast to the standard model, where markups are determined by the exogenously given elasticity of substitution between goods, markups are endogenously determined by the willingness to pay of households, and therefore by the distribution of income. Furthermore, unlike in the standard model firms cannot pass on trade costs so that markups on products sold abroad are lower than on products sold at home. In sum, at high levels of inequality not all goods produced are traded internationally, which is reminiscent of the Linder (1961) hypothesis, and at the same time, the incentives to innovate are high.

The introduction of non-homothetic preferences rises a number of interesting issues that don't arise in the standard model. For example, we can use our framework to discuss the design of intellectual property rights across countries. In particular, we argue that households in the poor country might not see eye to eye with households in the rich country on whether there should be national or international exhaustion of patents. We show that under a policy of national exhaustion compared to one of international exhaustion households in the rich country incur only losses since their consumption grows at a lower rate relative to a policy of international exhaustion whereas households in the poor country incur an additional static gain since they can consume a larger share of products. Whether the households in the two countries agree or disagree about patent policy depends crucially on how poor households weigh current gains against future losses.

Furthermore, we can analyze the consequences of a trade liberalization on trade patterns, the incentives to innovate, and relative welfare levels. We contend that a trade liberalization might increase the incentives to innovate, decrease the extensive margin of trade, and make households in the poor country worse off relative to households in the rich country. If trade costs fall from a level that sustains an equilibrium where all goods are traded to one that sustains an equilibrium where only a subset of all goods are traded, some firms in the rich country start to exclude households from the poor country due to the threat of parallel imports. This implies that resources are released from the production sector in the rich country, which have previously been used to satisfy the consumption needs of households in the poor country, that can now be allocated to the research sector. Hence, the world economy grows at a higher rate but at the same time the extensive margin of trade falls. One can then show that poor households become unambiguously worse off relative to rich households.

Grossman and Helpman (1991) initiated a vast literature that looks at the incentives to innovate in a global economy in general-equilibrium models with homothetic preferences. The literature that looks at the relationship between income inequality and growth, and in particular at the channels through which income inequality affects economic growth performance is much smaller, and suggests credit market imperfections or political economy mechanisms but neglects demand-side effects. Models that do consider demand-side effects are relatively few, and can be broadly divided into two categories. 
On the one hand, there are static models of international trade and non-homothetic preferences as in Foellmi et al. (2010), Markusen (2010), Matsuyama (2000) or Mitra and Trindade (2005) that focus on the effects of the demand side on trade patterns. On the other hand, there are dynamic models that analyze how the demand side shapes the incentives to innovate in closed economies like Foellmi and Zweimüller (2006).

Our model combines the static international setup from Foellmi et al. (2010) with the dynamic structure of Foellmi and Zweimüller (2006). In particular, our model nests the two models, i.e. it collapses to Foellmi and Zweimüller (2006) with no consumption hierarchy in the case of no trade costs and integrated factor markets, and to Foellmi et al. (2010) in the case where the time horizon becomes arbitrarily small (i.e. there is only "one" time period). This allows us to create a framework where the distribution of income across countries affects trade patterns and the incentives to innovate simultaneously. Hence, we can study the interdependence of trade and innovation in a global economy and compare our results to Grossman and Helpman (1991) where the distribution of income across countries is irrelevant due to the assumption of homothetic preferences. Additionally, our model enables us to discuss how trade policy, intellectual property rights in a global context, and the form of international knowledge spillovers affect the incentives to innovate. Issues on which the models by Foellmi et al. (2010) and Foellmi and Zweimüller (2006) are necessarily silent.

We proceed in our analysis as follows. We start in Section 2 by examining the closed economy with a focus on the difference between non-homothetic and standard CES preferences. In Section 3, we turn to the open economy where we study and discuss in detail the different equilibria, and under what conditions they emerge, and compare the model to Grossman and Helpman (1991). Afterwards, we analyze the effects of changes in income inequality across countries on the incentives to innovate, and the patterns of international trade. To illustrate the transitional dynamics we look at the example of a labor productivity increase in research and development in the poor country, which could be the result of a market or education reform. We then turn to applications and extensions issues in Section 5 , like how the design of intellectual property rights, trade policy, the form of international knowledge spillovers, or inequality within a country affects trade patterns and the innovation incentives. For the case of trade policy we also conduct a welfare analysis of a trade liberalization. Last, we look at how general our results are with respect to the assumptions about preferences in the baseline model. Section 6 concludes. 


\section{Closed Economy}

In this section we first discuss in detail the closed economy equilibrium with a representative household to gain as much intuition for the impact of preferences on innovation as possible before turning to the open economy case.

\subsection{Distribution and Endowments}

There is a total of $L$ identical households in the economy. This trivially allows for a representative household. Suppose that each household inelastically supplies $\theta$ efficiency units of labor in the labor market, and holds assets $a(t)$ (i.e. shares in firms). Hence, per capita income in period $t$ is given by $y(t)=w(t) \theta+r(t) a(t)$, where $w(t)$ denotes the wage rate per efficiency unit, and $r(t)$ the return on assets (i.e. interest rate).

\subsection{Households}

\subsubsection{Preferences}

The household's utility function is defined over a continuum of differentiated indivisible goods $j \in[0, \infty)$. At any point in time only a finite subset $N(t)$ is available in the market. All households have the same non-homothetic instantaneous utility function given by

$$
u\left(\{c(j, t)\}_{j=0}^{\infty}\right)=\int_{j=0}^{\infty} v(c(j, t)) d j
$$

where the baseline utility $v(c(j, t))$ is an indicator function $c(j, t) \in\{0,1\}$, and we normalize $v(0)=0$ and $v(1)=1$. This utility function satisfies the standard properties of positive and non-increasing marginal utility since the utility from consuming the first unit is one and the utility from consuming a second unit is zero, i.e. households are (locally) satiated. Note that the marginal utility from consuming an infinitesimal (in this case, zero) amount of any good $j$ is finite, i.e. $\lim _{c(j, t) \rightarrow 0} u^{\prime}(\cdot)=1<\infty$. Hence, the non-negativity constraints $c(j, t) \geq 0$ might become binding for some $j$ 's. Consequently, wealthy households will consume a different consumption bundle than poor households. For example, suppose that at some point in time the available set of indivisible goods consists of the following durables, a car, a washing machine, and a TV. In that case, affluent households can afford to purchase all durables whereas poor households might only afford to buy a TV. Put differently, households can only choose how many different goods they consume (extensive margin) but not how much of each good they consume (intensive margin). In this sense, zero-one preferences are the antipode of, and no less general than, constant-elasticity-of-substitution (CES) preferences, where households can only choose consumption 
along the intensive margin. In Section 5.5 we introduce quadratic preferences where households have a choice along the intensive and extensive margin of consumption. Last, note that all goods enter the utility function (2.1) symmetrically, i.e. there is no consumption hierarchy. A consumption hierarchy could be incorporated in the utility function by introducing a weighting function $\xi(j)$, which is decreasing in the index $j$ (see Foellmi and Zweimüller, 2006). This would imply that the marginal utility from consuming good $j$ is higher than from consuming good $k$, where $j<k$. Hence, households would first purchase low-indexed goods and as their incomes grow move on to higher-indexed goods. This would make the analysis substantially more complex without adding much insight to how inequality across countries affects trade and growth. However, it would allow us to make a statement about which country specializes in high-, respectively, low-indexed goods.

\subsubsection{Household problem}

We assume that a household has a logarithmic intertemporal utility function given by

$$
U(0)=\int_{t=0}^{\infty} e^{-\rho t} \log u\left(\{c(j, t)\}_{j=0}^{\infty}\right) d t
$$

where $u(\cdot)$ is given by $(2.1)$, and $\rho>0$ denotes the time preference rate. The household maximizes $(2.2)$ subject to its intertemporal budget constraint (2.3) given below, and the non-negativity constraints $c(j, t) \geq 0, \forall j, t$,

$$
\int_{t=0}^{\infty} e^{-R(t)}\left(\int_{j=0}^{\infty} p(j, t) c(j, t) d j\right) d t \leq a(0)+\int_{t=0}^{\infty} e^{-R(t)} w(t) \theta d t
$$

where $p(j, t)$ denotes the price of good $j$ at time $t, a(0)$ initial wealth of the household, and $R(t)=$ $\int_{s=0}^{t} r(s) d s$ the cumulative interest rate. Note that we imposed a no-Ponzi game condition of the following form $\lim _{t \rightarrow \infty} e^{-R(t)} a(t) \geq 0$ on the intertemporal budget constraint. Furthermore, we denote consumption expenditures in period $t$ by $e(t)=\int_{0}^{\infty} p(j, t) c(j, t) d j$. The first-order conditions (including complementary slackness conditions) to the household's optimization problem are given by

$$
\begin{aligned}
e^{-\rho t} \frac{u^{\prime}(\cdot)}{u(\cdot)}-\Lambda e^{-R(t)} p(j, t)+\mu(j, t) & =0 \\
\mu(j, t) c(j, t) & =0, \mu(j, t) \geq 0, c(j, t) \geq 0 \\
\int_{t=0}^{\infty} e^{-R(t)}\left(\int_{j=0}^{\infty} p(j, t) c(j, t) d j\right) d t & =a(0)+\int_{t=0}^{\infty} e^{-R(t)} w(t) \theta d t \\
\lim _{t \rightarrow \infty} e^{-\rho t} \lambda(t) a(t) & =0
\end{aligned}
$$


where $\Lambda$ denotes the (present value) Lagrange multiplier on the intertemporal budget constraint (note that the current value Lagrange multiplier on the budget constraint is given by $\left.\lambda(t)=\Lambda e^{-R(t)+\rho t}\right)$, and $\mu(j, t)$ the Lagrange multiplier on the non-negativity constraints. Note that due to the transversality condition the intertemporal budget constraint will always be binding in optimum (i.e. preferences exhibit global non-satiation).

We distinguish the following cases

(i) Non-negativity constraint is binding, i.e. $c(j, t)=0$. This implies by (2.5) that $\mu(j, t) \geq 0$. Hence, the first-order condition (2.4) can be written as follows

$$
e^{-\rho t} \frac{u^{\prime}(\cdot)}{u(\cdot)} \leq \Lambda e^{-R(t)} p(j, t)
$$

where the left-hand side denotes the marginal utility gain from consuming good $j$ and the righthand side denotes the marginal utility cost from consuming good $j$.

(ii) Non-negativity constraint is not binding, i.e. $c(j, t)>0$. This implies by $(2.5)$ that $\mu(j, t)=0$. Therefore, the first-order condition (2.4) can be written as follows

$$
e^{-\rho t} \frac{u^{\prime}(\cdot)}{u(\cdot)}=\Lambda e^{-R(t)} p(j, t)
$$

From equations (2.8) and (2.9) we can derive the household's Marshallian demand function for good $j$ as

$$
c(j, t)= \begin{cases}0, & p(j, t)>z(j, t) \\ 1, & p(j, t) \leq z(j, t)\end{cases}
$$

where $z(j, t) \equiv \frac{1}{\Lambda e^{-R(t)+\rho t}} u(\cdot)^{-1}$ denotes the household's willingness to pay for some good $j$. Intuitively, households compare the marginal utility gain of consuming 1 unit of good $j$, i.e. $e^{-\rho t} u^{\prime}(\cdot) / u(\cdot)$, with its associated marginal utility cost, i.e. $\Lambda e^{-R(t)} p(j, t)$. If the marginal utility gain exceeds or is equal to the marginal utility cost households purchase 1 unit of good $j$, otherwise they don't. Note that in equilibrium $u(\cdot)^{-1}=N(t)^{-1}$ will hold, where $N(t)$ denotes the number (set) of differentiated goods of which the household consumes one unit each. We see that the willingness to pay depends negatively on the Lagrange multiplier $\Lambda$, which can be interpreted as the marginal utility of (lifetime) wealth. The wealthier a household, the lower its marginal utility of wealth $\Lambda$, and therefore, holding everything else constant, the higher its willingness to pay $z(j, t)$. In other words, if a household becomes wealthier its willingness to pay for a given good will increase if it cannot expand its consumption to new goods, 
i.e. increase $N(t)$. This is the case because households have no choice about how much they want to consume of each good (intensive margin). Furthermore, the more different goods a household consumes, i.e. the higher $N(t)$, the lower its willingness to pay for a given good $j$, ceteris paribus.

Summing over individual household demands (2.10) yields aggregate or market demand for good $j$

$$
X(p(j, t))= \begin{cases}0, & p(j, t)>z(j, t) \\ L, & p(j, t) \leq z(j, t)\end{cases}
$$

The step function in Figure 1 below depicts aggregate demand for good $j$. From Figure 1 we can derive the price elasticity of aggregate demand $\varepsilon \equiv-X^{\prime}(p(j, t)) p(j, t) / X(p(j, t))$ as follows. On the one hand, if firm $j$ increases its price $p(j, t)$ to a price above $z(j, t)$ its demand drops to zero, implying that aggregate demand is infinitely price elastic for $p(j, t)>z(j, t)$, i.e. the price elasticity $\varepsilon \rightarrow \infty$. On the other hand, if firm $j$ increases its price to any price below or equal to $z(j, t)$ its demand remains unchanged. Hence, aggregate demand is perfectly inelastic for $p(j, t)<z(j, t)$, i.e. the price elasticity $\varepsilon \rightarrow 0$. In other words, for price changes below $z(j, t)$ households always consume 1 unit of good $j$ regardless of its price (this is an implication of local satiation in households' preferences).

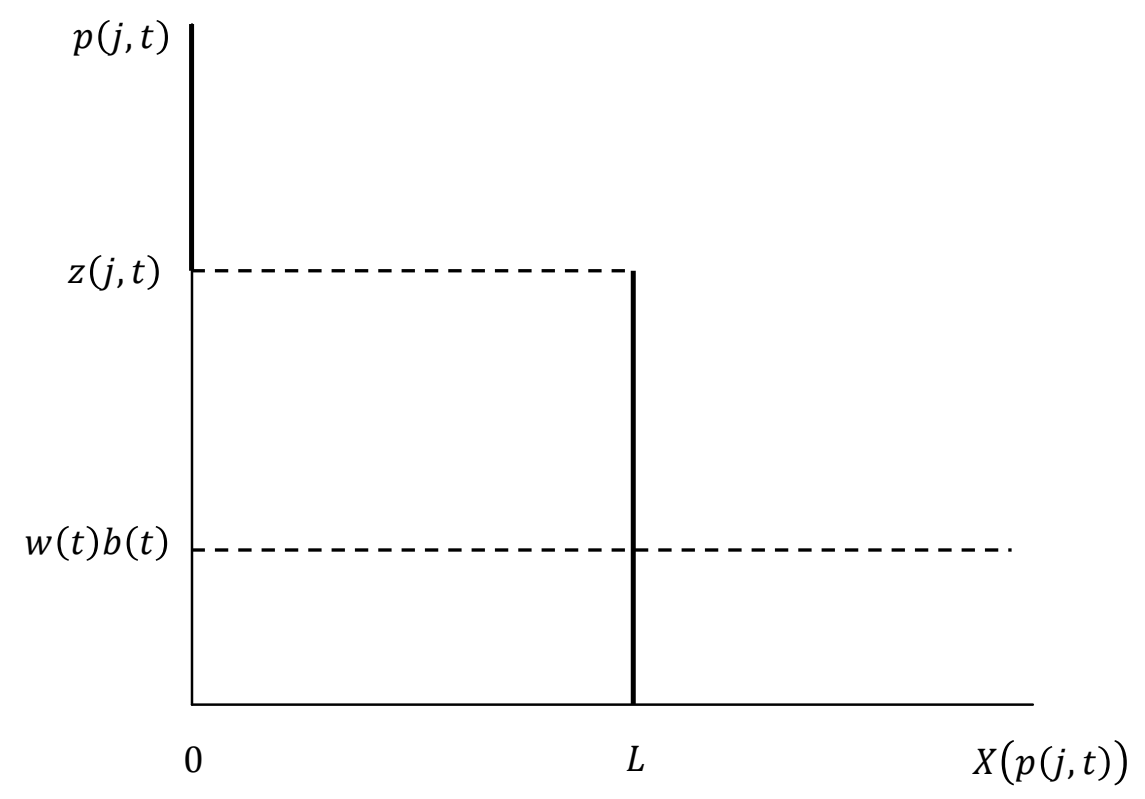

Figure 1: Aggregate demand for good $j$ in period $t$ 


\subsection{Firms}

\subsubsection{Technology}

Firms have access to the following technology. A firm must hire $F(t)=F / N(t)$ units of labor in the labor market up-front to do research and development (R\&D) of a new product. Each firm will develop and produce only one (unique) good. Firms raise the necessary capital to finance their R\&D projects by issuing shares in the capital market. Remember that $N(t)$ denotes the stock of products (or knowledge imbedded in these products) which have been developed in the economy up to time $t$. This implies that there are intertemporal knowledge spillovers (as in Romer, 1990, ideas are non-excludable and non-rival). In other words, the more products have been developed in the past the more productive is labor in the research lab ("standing on the shoulders of giants"). Once a new product has been developed the production of 1 unit of output requires $b(t)=b / N(t)$ units of labor to produce. Note that intertemporal spillovers carry over to the production sector. New products are protected by patents which grant the developing firms perpetual monopolies.

\subsubsection{Firm problem}

Firm $j$ maximizes operating profits

$$
\pi(j, t)=[p(j, t)-w(t) b(t)] X(p(j, t))
$$

subject to its aggregate demand $X(p(j, t))$ given by $(2.11)$. The first-order condition is given by

$$
\frac{p(j, t)-w(t) b(t)}{p(j, t)}=\frac{1}{\varepsilon}
$$

where the left-hand side denotes the Lerner index (i.e. the ratio of profit margin, i.e. price minus marginal cost, and the price), and the right-hand side denotes the inverse of the price elasticity of aggregate demand $\varepsilon$. It follows that the markup, i.e. the ratio of price $p(j, t)$ to marginal $\operatorname{cost} w(t) b(t)$, is determined by $\mathcal{M} \equiv\left(1-\frac{1}{\varepsilon}\right)^{-1}$. We make two observations. First, the monopolist always operates in a price region where the price elasticity of aggregate demand $\varepsilon$ exceeds 1 . In the region where the elasticity is less than 1 , the monopolist's revenue and his profits are increasing in price and decreasing in quantity (see Tirole, 1988). Second, the markup $\mathcal{M}$ is decreasing in the price elasticity of aggregate demand $\varepsilon$.

From the first-order condition (2.13) of firm $j$ we can derive the optimal price as follows. Note that in the case the price elasticity $\varepsilon$ is infinitely high, firms cannot exert their market power (i.e. markups $\mathcal{M}$ go to 1 as $\varepsilon \rightarrow \infty)$ and prices drop to marginal cost $w(t) b(t)$. We assume that marginal costs 
fall short of the willingness to pay (see Figure 1). Otherwise, no producer would ever earn positive profits. At marginal cost pricing firm $j$ does not earn any (economic) profits needed to recoup the fixed cost $w(t) F(t)$ paid up-front for product development. Hence, firm $j$ would never increase its price above the willingness to pay $z(j, t)$ and run losses. In the other case, where aggregate demand is perfectly inelastic, i.e. the price elasticity $\varepsilon$ is zero, the monopolist does not operate. If firm $j$ sets a price below the willingness to pay it could increase its price without loosing demand, and therefore increase its revenue and profits. Hence, the highest price firm $j$ can set is equal to the willingness to pay $z(j, t)$. This is the price at which marginal revenue equals marginal cost. We conclude that the profit-maximizing price for firm $j$ is given by

$$
p(j, t)=z(j, t)
$$

With CES preferences the markup $\mathcal{M}$ is exogenously determined by the elasticity of substitution between goods whereas in the case of zero-one preferences the markup is endogenously given by $\mathcal{M}=z(j, t) / w(t) b(t)$. Given marginal cost, the markup increases if the willingness to pay of households increases. This implies that the higher the willingness to pay, the lower the price elasticity of demand, ceteris paribus.

\subsection{Equilibrium}

\subsubsection{Goods market}

In equilibrium, a finite set $N(t)$ of differentiated goods is available on the market. From optimal prices (2.14) follow optimal quantities in equilibrium. Since all firms face the same demand curve (1) and have the same cost structure, they all charge the same price $p(t)=z(t)$ equal to the willingness to pay of households, and supply the same quantity given by

$$
X=L, \forall t
$$

From the first-order condition (2.9) follows that optimal consumption expenditures grow at the following rate

$$
\frac{\dot{e}(t)}{e(t)}=r(t)-\rho
$$

where $u^{\prime}(\cdot) / u(\cdot)=1 / N(t)$ since $c(t)=1$ for all $j$ 's consumed in equilibrium. 


\subsubsection{Labor market}

The labor market clears in every period. Because labor is mobile across sectors, i.e. all households can work in the production or the $\mathrm{R} \& \mathrm{D}$ sector, there is one wage rate at which the labor market clears. Labor market clearing is determined by

$$
\begin{aligned}
L \theta & =\dot{N}(t) F(t)+\int_{j=0}^{N(t)} b(t) X(j, t) d j \\
L \theta & =\frac{\dot{N}(t)}{N(t)} F+b L
\end{aligned}
$$

where the left-hand side denotes exogenous aggregate labor supply, and the right-hand side aggregate labor demand from the R\&D and production sector. Note that labor demand from the production sector is determined only by technology parameter $b$ and population size $L$ due to the constant intensive margin of consumption, i.e. $c(j, t)=1$ for all $j, t$.

\subsubsection{Capital market}

We assume perfect capital markets. On perfect capital markets, the present discounted value of profits equals the stock market value of the firm (i.e. there are no asset bubbles). Since all firms make identical profits the present discounted value of profits is determined by

$$
v(t)=\int_{\tau=t}^{\infty} e^{-R(\tau)} \pi(\tau) d \tau
$$

where equilibrium profits in period $t$ are determined by $\pi(t)=[z(t)-w(t) b(t)] L$. Differentiating $(2.18)$ with respect to time $t$ yields the familiar arbitrage condition

$$
\pi(t)+\dot{v}(t)=r(t) v(t)
$$

which says that the return on an investment of size $v(t)$ in any firm, i.e. the dividend $\pi(t)$ paid plus capital gains/losses $\dot{v}(t)$, must equal the return on an investment of size $v(t)$ in risk-less bonds. We assume that there is free entry into product development. There is firm-entry as long as the value of a firm $v(t)$ is equal to or exceeds the fixed cost of product development $w(t) b(t)$. Hence, in an equilibrium with positive growth free entry implies the following zero-profit condition

$$
v(t)=w(t) F(t)
$$


Capital market clearing requires that savings equal investment, i.e. aggregate asset holdings $A(t)=$ $L a(t)$ must equal the stock market value of firms $\int_{j=0}^{N(t)} v(t) d j=N(t) v(t)$. The interest rate $r(t)$ adjusts such that the capital market clears in every period $t$.

\subsection{Steady state}

We consider a steady state in which all variables grow at the same constant rate $g>0$. Hence, prices, quantities, profits, the interest rate, and the shares of labor allocated to production and $R \& D$ are constant in the steady state.

Equations (2.15)-(2.20) completely characterize the steady state. We choose the marginal cost of production as the numeraire $w(t) b(t)=1$. The equations can be reduced to the labor market clearing condition and the zero-profit condition

$$
\begin{aligned}
L \theta & =g F+b L \\
\frac{(z-1) L}{g+\rho} & =\frac{F}{b}
\end{aligned}
$$

Remember that because the intensive margin of consumption is constant the share of labor allocated to the production sector is determined entirely by technology and population size in equilibrium, and the residual share of labor is allocated to $\mathrm{R} \& \mathrm{D}$. Hence, the solution for the growth rate of the economy $g$ is pinned down by the labor market clearing condition

$$
g=\frac{1}{F}(\theta-b) L>0, \Leftrightarrow \theta>b
$$

In other words, the growth rate $g$ is determined such that labor demand and labor supply equalize, i.e. the labor market clears. It follows that equilibrium prices $z=(L \theta+F \rho) / b L$ and markups adjust such that the zero-profit condition holds, i.e. are consistent with free entry into product development.

\subsection{Discussion}

In this discussion we focus on the consequences of endogenous markups in our model. This highlights the difference to the standard model of Grossman and Helpman (1991) with CES preferences where markups are exogenously determined.

We start by observing that the growth rate is independent of the preference parameter $\rho$. In the steady state, an increase in $\rho$ has too opposing effects on the growth rate $g$, which cancel each other. On the one hand, an increase in $\rho$ leads to an increase in the interest rate $r$. This tends to decrease the growth rate $g$ through its negative effect on the present discounted value of profits. On 
the other hand, an increase in $\rho$ leads to an increase in markups and prices $z$, which tends to increase profits and therefore the growth rate $g$. In the steady state, these two effects offset each other. To understand the intuition behind this result consider a ceteris paribus increase in the time preference rate $\rho$, i.e. households become more impatient (discount future consumption more heavily). In other words, households prefer even more to consume today instead of tomorrow (less willing to postpone consumption). As in standard models of endogenous growth, if households are less willing to save the interest rate $r$ needed to equate savings with investments must increase. In the model with CES preferences where markups are exogenous (determined by the elasticity of substitution between goods) a change in $\rho$ leaves markups and prices unchanged. The increase in $r$ then leads to a lower present discounted value of profits, and hence a lower incentive to innovate. However, in this model, markups are endogenously determined by the willingness to pay of households. If households become more impatient their willingness to pay for goods (today relative to tomorrow) increases such that markups and prices rise.

\section{Open Economy}

In this section, we turn to the case of the open economy. Suppose that there are two countries or regions indexed by $i=\{R, P\}$. We allow goods to be traded across countries at iceberg trade $\operatorname{costs} \tau \geq 1$. This implies that to ensure one unit of a good arrives at its destination, $\tau \geq 1$ units of that good have to be shipped.

\subsection{Distribution and Endowments}

There is a total of $L$ households in the two countries. A fraction $\beta$ of the total population lives in country $P$ whereas the rest $1-\beta$ lives in country $R$. Suppose that each household in country $i$ inelastically supplies $\theta_{i}$ efficiency units of labor in their domestic labor market. In particular, we assume that labor is immobile across countries but is mobile across sectors within a country. We further assume that each household holds only domestic assets (i.e. there is a perfect home bias in their portfolios). Hence, inequality in the endogenously determined (personal) income distribution across countries originates from differences in labor and capital incomes (factor incomes) across countries. We will assume that households in country $R$ are wealthier than households in country $P$. Therefore, we will sometimes refer to country $R$ as the rich country and country $P$ as the poor country.

Suppose that there exists an institution which levies a lump-sum $\operatorname{tax} T_{R}(t)>0$ in the rich country in each period and redistributes the tax revenues as lump-sum benefits $T_{P}(t)>0$ to households in the poor country. We impose that the institution runs a balanced budget in each period, i.e. total tax revenues 
$(1-\beta) L T_{R}(t)$ equal total tax spending $\beta L T_{P}(t)$. Hence, we can choose the level of $T_{P}(t)=T(t)$ as our exogenous variable, which implies that $T_{R}(t)=\beta T(t) /(1-\beta)$. We will assume that over time transfers grow at the same constant rate $g$ as incomes, i.e. $T(t)=T(0) e^{g t}$. This assumption is necessary to generate a steady state in which the distribution of income across countries is stationary. Changes in lump-sum transfers will allow us to study ceteris paribus changes in inequality across countries, i.e. without changing relative country sizes, labor endowments or technology at the same time. One way to think about these transfers is foreign aid. We will measure income inequality across countries in the steady state with the help of the Gini coefficient (for a derivation see Appendix 7.1).

\subsection{Households}

All households maximize intertemporal utility $(2.2)$, where instantaneous utility $u(\cdot)$ is given by $(2.1)$, subject to their intertemporal budget constraint (2.3) and the non-negativity constraints $c_{i}(j, t) \geq 0$. Note that all households have the same preferences regardless of their country of residence. The resulting aggregate demand for good $j$ is given by

$$
X(p(j, t))= \begin{cases}0, & p(j, t)>z_{R}(j, t) \\ (1-\beta) L, & z_{P}(j, t)<p(j, t) \leq z_{R}(j, t) \\ L, & p(j, t) \leq z_{P}(j, t)\end{cases}
$$

where $z_{i}(j, t)$ denotes the willingness to pay of households in country $i$ for good $j$. Note that because households in country $R$ are wealthier than households in country $P$ their marginal utility of wealth $\lambda_{R}(t)$ is higher. This implies that they have a higher willingness to pay for good $j$, i.e. $z_{R}(j, t)>z_{P}(j, t)$, holding the set of goods consumed $N_{i}(t)$ constant. Furthermore, we note that wealthy households have a relatively low price elasticity of demand. Figure 2 shows the aggregate demand function (3.1) for good $j$. 


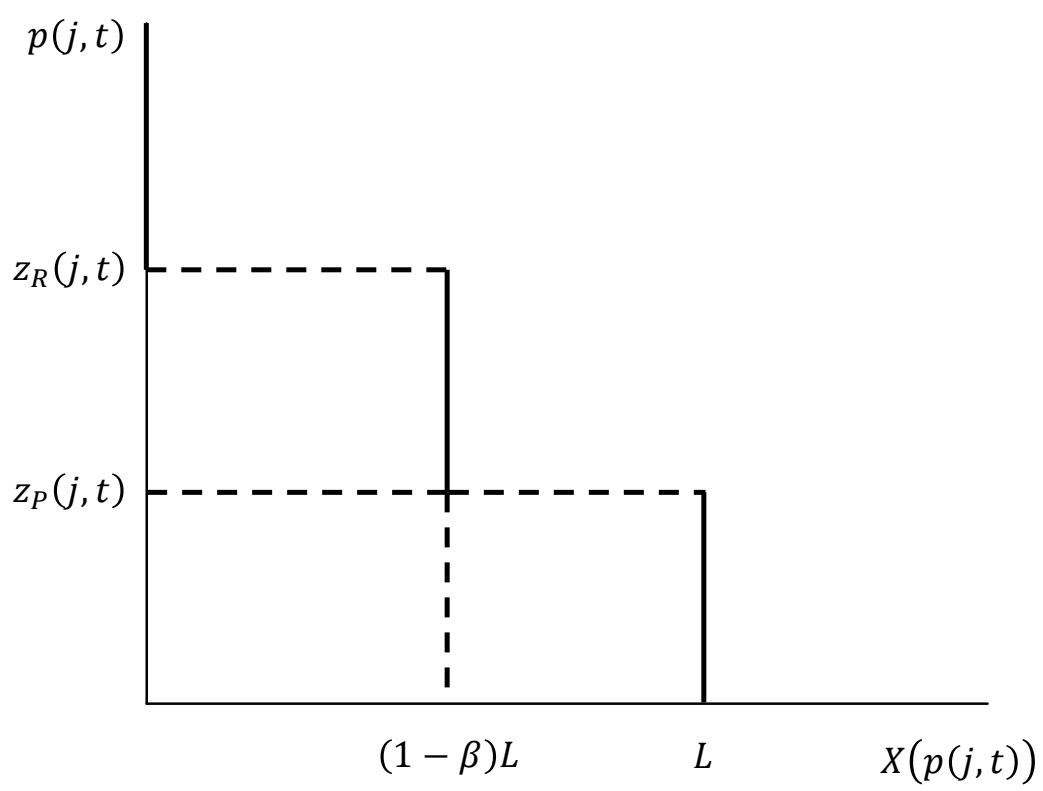

Figure 2: Aggregate demand for good $j$ in period $t$

\subsection{Firms}

\subsubsection{Technology}

Firms located in country $i$ have access to the following technology (which we allow to differ across countries). A firm must hire $F^{i}(t)=F^{i} / N(t)$ units of labor in the domestic labor market up-front to do research and development $(\mathrm{R} \& \mathrm{D})$ of a new product. Each firm will develop and produce only one (unique) good. Firms raise the necessary capital to finance their R\&D projects by issuing shares in their domestic capital market. Note that $N(t)$ denotes the stock of products (or knowledge imbedded in these products) which have been developed in the world economy up to time $t$, i.e. $N(t)=\sum_{i} N^{i}(t)$. This implies that there are international, intertemporal knowledge spillovers like in Grossman and Helpman (1991). Coe and Helpman (1995) find empirical evidence for the existence of international R\&D spillovers. Their estimates suggest that foreign R\&D has beneficial effects on domestic productivity, and that these effects are stronger the more open an economy is to foreign trade. In Section 5.3 we relax this assumption, and look at the consequences of imperfect international knowledge spillovers. As in Grossman and Helpman (1991), we note that trade, i.e. the integration of product markets, introduces competition among innovators across countries. This implies that firms in both countries have an incentive to develop new products that are unique in the world, and therefore trade eliminates duplication of research and development across countries. To see this, suppose that a firm in country $i$, with access to the technology described above, develops a product that already exists in country $k \neq i$. Ex post Bertrand (i.e. price) competition between the entrant and the incumbent would result 
in a limit price equal to the highest marginal cost, at that point the firm with the relatively higher marginal cost drops out of the market. Hence, the monopoly profits a firm earns from capturing an existing market (i.e. copying an existing product) are strictly lower than the monopoly profits from opening up a new market (i.e. developing a novel product). In other words, the strategy of imitating an existing product is always strictly dominated by the strategy to develop a novel product. Once a new product has been developed the production of 1 unit of output requires $b^{i}(t)=b^{i} / N(t)$ units of domestic labor to produce. New products are protected by internationally exhausted patents which grant the developing firms perpetual monopolies. Note that internationally exhausted patents imply that parallel imports are legal. In Section 5.1.1 we take a closer look at the design of international property rights and their effects on trade patterns and the incentives to innovate.

\subsubsection{Firm problem}

Firm $j$ maximizes profits (2.12) subject to its aggregate demand (3.1) and subject to a price setting restriction implied by the international exhaustion of patents (i.e. the threat of parallel imports). The profit maximizing behavior of firm $j$ is stated in Proposition 1 below.

Proposition 1. In the case, where (i) the willingness to pay of households in the rich country, $z_{R}(j, t)$ falls short of the willingness to pay of households in the poor country $z_{P}(j, t)$ times trade costs $\tau$, firms can perfectly price discriminate across countries. In the case, where (ii) the willingness to pay in the rich country $z_{R}(j, t)$ exceeds or is equal to the one in the poor country $z_{P}(j, t)$ times trade costs $\tau$, the price setting power of firms is limited.

Proof. Let us first prove case (ii) of the proposition. Suppose that $z_{R}(j, t) \geq \tau z_{P}(j, t)$ with $\tau>1$. Firm $j$ located in country $R$ would like to choose prices in the rich and poor country such that its profits

$$
\pi_{R}(j, t)=\left[p_{R}^{R}(j, t)-w^{R}(t) b^{R}(t)\right](1-\beta) L+\left[p_{P}^{R}(j, t)-\tau w^{R}(t) b^{R}(t)\right] \beta L
$$

are maximized, where $w^{R}(t)$ denotes the wage rate in the rich country, $p_{R}^{R}(j, t)$ the price of good $j$ in the rich country, and $p_{P}^{R}(j, t)$ the price in the poor country. The first term in (3.2) denotes profits earned on the domestic market and the second term profits earned from serving the foreign market. We assume $p_{P}^{R}(j, t) \geq \tau w^{R}(t) b^{R}(t)$. Otherwise, firm $j$ in the rich country would make a loss on each unit it exports to the poor country and would therefore never export. Recall our discussion in Section 2.3 about optimal price setting of monopolistic firms. Hence, in the export market firm $j$ would like to set a price equal to the willingness to pay of households in the poor country $z_{P}(j, t)$, and in the domestic market a price equal to the willingness to pay of households in the rich country. Suppose firm $j$ would set a price in the domestic market equal to $z_{R}(j, t)$ and in the export market equal to $z_{P}(j, t)$. 
Since $z_{R}(j, t) \geq \tau z_{P}(j, t)$ arbitrageurs could make positive profits by buying good $j$ on the grey market in the poor country at low prices $z_{P}(j, t)$, and importing it back to the rich country at cost $\tau$, where they could sell it at a price marginally lower than $z_{R}(j, t)$. This threat forces firm $j$ to set a limit price equal to $\tau z_{P}(j, t)$ in the rich country if it doesn't want to loose all demand to arbitrageurs. The same argument holds for a firm $j$ producing in the poor country and exporting to the rich country. Hence, if $z_{R}(j, t) \geq \tau z_{P}(j, t)$ the firm's price setting power is limited by the threat of parallel imports, i.e. the price setting restriction imposed by internationally exhausted patents becomes binding. The proof of part $(i)$ is straightforward. If $z_{R}(j, t)<\tau z_{P}(j, t)$, the arbitrage described above is not profitable, and therefore firms can perfectly price discriminate across countries. Consider the special case of no trade cost, i.e. $\tau=1$. Since $z_{R}(j, t)>z_{P}(j, t)$ at any point in time, firm $j$ engaged in international sales is always restricted in its price setting power due to the threat of parallel imports. Hence, firm $j$ exporting its good is forced to set a limit price of $z_{P}(j, t)$ in the rich country, and case $(i)$ never occurs.

\subsection{Equilibrium}

From Proposition 1 follows another proposition, which determines the structure of the equilibrium.

Proposition 2. Proposition 1 implies that in case (ii) not all firms producing in the rich country export to the poor country, and in case (i) all firms export in equilibrium.

Proof. Suppose that in case (ii) all firms would sell in the rich country at prices $\tau z_{P}(t)$. Since $\tau z_{P}(t)<$ $z_{R}(t)$ for all goods $j$ this implies that households in the rich country would not exhaust their budget constraints. Hence, their willingness to pay for an additional good would be infinitely high. This would induce some firms producing in the rich country to sell their goods exclusively in their domestic market. Since these firms don't export they are not subject to the threat from parallel imports, and can set prices equal to the willingness to pay of rich households. In equilibrium, there exist two types of firms producing in the rich country, the ones that export, and the ones that don't, whenever both types of firms earn the same profits. Since firms manufacturing in the poor country have to incur transportation cost if they export, it is never a dominant strategy for these firms to sell exclusively in the rich country. In case $(i)$, the price setting restriction does not bind and no firm has an incentive to sell exclusively in the rich country, given exporting is profitable in the first place.

Let us call case ( $i$ ) a full-trade equilibrium, and case (ii) a part-trade equilibrium. In other words, if inequality across countries is high for a given level of trade costs, or trade costs are low for a given level of inequality, only part of all goods produced in the rich country will be traded such that the economy is in a part-trade equilibrium. Note that this is the same equilibrium structure as in the static model of Foellmi et al. (2011). 
The model suggests that parallel imports and price discrimination across countries on the basis of differences in per capita incomes are important characteristics of an open economy. First, both casual observation and anecdotal evidence suggest that parallel imports might not be unimportant in reality. Maskus and Chen (2004) state that it is difficult to measure how important parallel imports are since they are generally not recorded. However, according to them, survey evidence suggests that they can capture a sizable share of markets for specific products where parallel trade is allowed. Furthermore, there is numerous anecdotal evidence which suggests that parallel imports are far from irrelevant in reality. For example, in 2008, the consultancy KPMG, estimated the size of the IT grey market at about eight percent of total global IT sales (see KPMG, 2008). In the Economist (1998) among other examples the car maker Honda claims to have lost as much as a quarter of its British sales to parallel imports in 1998, and the British supermarket chain Tesco has been enjoined from selling Levi's jeans cheaper than authorized sellers. Simonovska (2010) provides empirical evidence that per capita incomes and the prices of homogeneous tradable goods are positively related.

We close the discussion of the equilibrium with a comparison of the equilibrium structure to the standard case of CES preferences. In the standard model discussed in Grossman and Helpman (1991) case (ii), a part-trade equilibrium, can never occur. The reason is the following. In the case of CES preferences the marginal utility from consuming an infinitesimal quantity of good $j$ is infinitely high. Therefore all households will always consume all goods available even in the presence of trade costs, i.e. $1<\tau<\infty$. In other words, the restriction in Proposition 1 that the price charged in country $R$ cannot exceed the price charged in country $P$ times trade costs $\tau$ is never binding. We conclude that the introduction of non-homothetic preferences of the zero-one form implies a different equilibrium structure where the degree of inequality across countries determines trade patterns, and as we will see below, simultaneously the incentives to innovate.

\subsection{Full-trade Equilibrium}

In this section, we discuss case $(i)$ implied by Proposition 2. In a full-trade equilibrium, all households in both countries consume all goods available on the world market. However, households in the rich country pay higher prices for the same consumption bundle, i.e. firms fully skim their higher willingness to pay.

\subsubsection{Goods markets}

In equilibrium, a finite set $N(t)$ of differentiated goods is available on the market in the rich and poor country. Note that $N(t)=N^{P}(t)+N^{R}(t)$ where $N^{i}(t)$ denotes the set of differentiated goods produced 
in country $i$.

Proposition 2 implies that in a full-trade equilibrium all goods sold in country $i$ command the same prices equal to the willingness to pay of households in country $i$, i.e. $z_{i}(t)$, regardless of where they are produced. Hence, all firms supply the following quantities in equilibrium

$$
X=L, \forall t
$$

From the first-order condition (2.9) follows the Euler equation for households in country $i$

$$
\frac{\dot{e}_{i}(t)}{e_{i}(t)}=r^{i}(t)-\rho
$$

where $e_{i}(t)=N_{i}(t) z_{i}(t)$ denotes nominal consumption expenditures, $N_{i}(t)$ the set of goods consumed, and $r^{i}(t)$ the interest rate in country $i$. In equilibrium, we have $N_{i}(t)=N(t)$ for households in both countries.

\subsubsection{Labor markets}

Remember that labor is immobile across countries but mobile across production and R\&D sectors within countries. Labor market clearing in the rich country is determined by

$$
(1-\beta) L \theta_{R}=\frac{\dot{N}^{R}(t)}{N^{R}(t)}[1-\zeta(t)] F^{R}+[1-\zeta(t)] b^{R}(1-\beta) L+[1-\zeta(t)] \tau b^{R} \beta L
$$

where $\zeta(t) \equiv N^{P}(t) / N(t)$ such that $1-\zeta(t)=N^{R}(t) / N(t)$ denotes the production share of the poor, respectively, the rich country. The left-hand side denotes aggregate labor supply in the rich country whereas on the right-hand side the first term denotes labor demand from the R\&D sector, and the second and third term labor demand from the production sector (supplying domestic and export markets). Similarly, in the poor country labor market clearing is given by

$$
\beta L \theta_{P}=\frac{\dot{N}^{P}(t)}{N^{P}(t)} \zeta(t) F^{P}+\zeta(t) b^{P} \beta L+\zeta(t) \tau b^{P}(1-\beta) L
$$

\subsubsection{Capital markets}

We assume that capital is immobile across countries. Capital markets in each country are perfect such that the present discounted value of profits equals the stock market value of domestic firms. Since all firms within country $i$ have the same demand and cost functions they all make identical profits. Hence, 
the present discounted value of profits for a firm located in country $i$ is given by

$$
v_{i}(t)=\int_{t}^{\infty} e^{-r^{i}(\tau)} \pi_{i}(\tau) d \tau
$$

where $\pi_{i}(t)$ is given by (3.2) and its correspondence for firms in the poor country. Differentiating (3.7) with respect to time yields the arbitrage condition for country $i$

$$
\pi_{i}(t)+\dot{v}_{i}(t)=r^{i}(t) v_{i}(t)
$$

We assume there is free entry into product development in country $i$. There is firm-entry as long as the value of a firm $v_{i}(t)$ is equal to or exceeds the fixed cost of product development $w^{i}(t) b^{i}(t)$. Hence, in an equilibrium with positive growth the zero-profit condition for country $i$ implied by free entry is given by

$$
v_{i}(t)=w^{i}(t) F^{i}(t)
$$

Capital market clearing in country $i$ requires that domestic savings equal domestic investment, i.e. aggregate asset holdings $A_{i}(t)$ must equal the stock market value of firms $\int_{j=0}^{N^{i}(t)} v_{i}(t) d j=N^{i}(t) v_{i}(t)$. The interest rate $r^{i}(t)$ adjusts such that the capital market in country $i$ clears in every period.

\subsubsection{Balance of Payments}

We will assume that the balance of payments is balanced period by period. Since we assume that capital is immobile across countries (i.e. foreign ownership of domestic assets is not allowed) the capital account, which keeps track of the net change in national ownership of assets, is always balanced. Hence, the current account ${ }^{2}$ must also be balanced in every period. In other words, we require that the sum of the balance of trade plus net transfer payments is zero. Hence, the balance of payments is given by (for a detailed derivation see Appendix 7.2.1)

$$
\left[\beta L N^{R}(t) z_{P}(t)-(1-\beta) L N^{P}(t) z_{R}(t)\right]-\beta L T_{P}(t)=0
$$

where the first term in brackets on the left-hand side denotes the balance of trade and the second term net transfer payments. Hence, if there is a progressive transfer $T_{P}(t)>0$ it must be that the balance of trade is negative for the poor country, i.e. the value of its imports exceeds the value of its exports. The poor country then runs a permanent trade deficit financed by transfers from the rich country.

\footnotetext{
${ }^{2}$ The current account is the sum of the balance of trade, net factor payments and net transfer payments. Since capital and labor are not mobile across countries net factor payments are zero.
} 


\subsubsection{Steady state}

We consider a steady state in which all variables in both countries grow at the common constant rate $g>0$. Hence, in each country prices, quantities, profits, the interest rate, and the share of labor allocated to production and R\&D are constant in the steady state. Note that since households in both countries have identical homothetic intertemporal preferences they have the same marginal propensity to save. Hence, households desire the same optimal growth of consumption expenditures in the steady state. This implies that interest rates are identical across countries in a steady state where incomes in both countries grow at the same rate. Equations (3.3)-(3.10) completely determine the full-trade steady state. We choose the marginal cost of production for firms located in the poor country as the numeraire and set $w^{P}(t) b^{P}(t)=1$. For completeness the equations describing the steady state are stated in Appendix 7.2.2.

In Figure 3 we solve graphically for the steady state growth rate $g$ and production share of the poor country $\zeta$, which are determined by the (unique) intersection of the labor market clearing conditions (3.11) and (3.12), which are reproduced below for convenience

$$
\begin{aligned}
(1-\beta) L \theta_{R} & =g(1-\zeta) F^{R}+(1-\zeta) b^{R}(1-\beta) L+(1-\zeta) \tau b^{R} \beta L \\
\beta L \theta_{P} & =g \zeta F^{P}+\zeta b^{P} \beta L+\zeta \tau b^{P}(1-\beta) L
\end{aligned}
$$

We state the conditions under which a unique steady state exists in the following proposition.

Proposition 3. A unique steady state with a positive growth rate $g>0$ and production share of the poor country $\zeta>0$ exists if $g(\zeta=0) \rightarrow \infty$ and $g(\zeta=1)>0$ in equation (3.12) and $g(\zeta=1) \rightarrow \infty$ and $g(\zeta=0)>0$ in equation (3.11). Otherwise, the steady state features stagnation, i.e. $g=0$.

Proof. The proof follows by the properties of (3.11) and (3.12). 


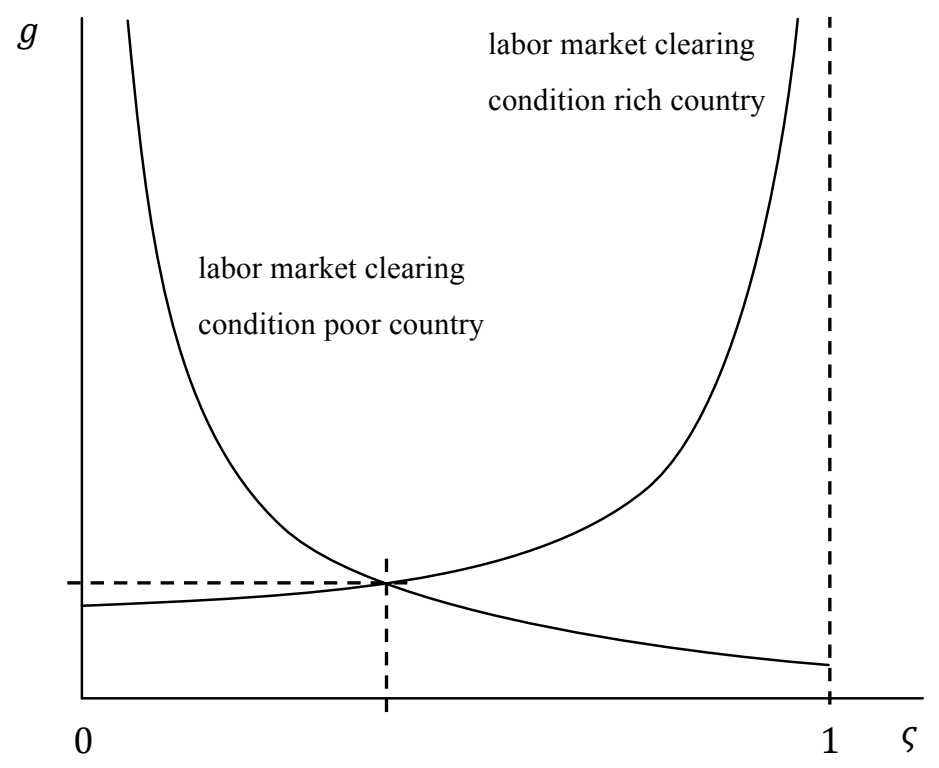

Figure 3: Steady state full-trade equilibrium

\subsection{Part-trade Equilibrium}

This section discusses case $(i i)$ implied by Proposition 2. Households in the rich country consume all goods available on the world market whereas households in the poor country consume only a subset of all goods available. Firms cannot perfectly price discriminate across countries due to the imminent threat of parallel imports. Some firms located in the rich country don't export, i.e. they forgo a larger market in order to be able to charge higher prices (unconstrained price-setting), whereas all firms located in the poor country export (constrained price-setting). Note that we keep all the assumptions made in the full-trade equilibrium concerning the economic environment.

\subsubsection{Goods markets}

In equilibrium, a finite set $N(t)=N^{R}(t)+N^{P}(t)$ of differentiated goods is available on the market in the rich country whereas only a subset $N_{P}(t)<N(t)$ is available on the market in the poor country.

Proposition 2 implies that in a part-trade equilibrium goods are priced as follows. All goods sold in the poor country command the same prices equal to the willingness to pay of households in the poor country $z_{P}(t)$. In the rich country, all goods that are not exported are priced at the willingness to pay of households in the rich country $z_{R}(t)$, whereas all goods that are sold in the rich and poor country (regardless of where they are produced) command prices equal to trade costs times the willingness to pay of households in the poor country $\tau z_{P}(t)$. Hence, all firms located in the rich country that don't 
export supply the following quantities in equilibrium

$$
X=(1-\beta) L, \forall t
$$

All firms that engage in international trade, regardless of their location, supply the following quantities in equilibrium

$$
X=L \forall t
$$

From the first-order condition (2.9) follows the evolution of optimal consumption expenditures $e_{i}(t)$ for households in country $i$

$$
\frac{\dot{e}_{i}(t)}{e_{i}(t)}=r^{i}(t)-\rho
$$

\subsubsection{Labor markets}

Labor market clearing in the part-trade equilibrium is determined as follows. In the rich country, labor market clearing is given by

$$
(1-\beta) L \theta_{R}=\frac{\dot{N}^{R}(t)}{N^{R}(t)}[1-\zeta(t)] F^{R}+[1-\zeta(t)] b^{R}(1-\beta) L+\Omega(t)[1-\zeta(t)] \tau b^{R} \beta L
$$

where $\zeta(t) \equiv N^{P}(t) / N(t)$ denotes the production share of the poor country, and $\Omega(t) \equiv N_{M}^{R}(t) / N^{R}(t)$ denotes the share of exporters in the rich country, i.e. the extensive margin of trade. Again, the lefthand side denotes aggregate labor supply and the right-hand side aggregate labor demand from the $\mathrm{R} \& \mathrm{D}$ and production sectors. Labor market clearing in the poor country is determined by

$$
\beta L \theta_{P}=\frac{\dot{N}^{P}(t)}{N^{P}(t)} \zeta(t) F^{P}+\zeta(t) b^{P} \beta L+\zeta(t) \tau b^{P}(1-\beta) L
$$

which is identical to the full-trade equilibrium.

\subsubsection{Capital markets}

Proposition 2 implies that in a part-trade equilibrium firms located in the rich country must be indifferent whether to export or not. In other words, profits of firms that export $\pi_{R, M}(t)$, i.e. pursue a mass strategy, must equal profits of firms that don't export $\pi_{R, E}(t)$, i.e. pursue an exclusive strategy. Hence, 
the following arbitrage condition for profits must hold in the rich country

$$
\pi_{R, M}(t)=\pi_{R, E}(t)=\pi_{R}(t)
$$

It follows that all firms in country $i$ earn identical profits, and the present discounted value of profits is given by

$$
v_{i}(t)=\int_{t}^{\infty} e^{-r^{i}(\tau)} \pi_{i}(\tau) d \tau
$$

The corresponding arbitrage condition for the capital market in country $i$ is determined by

$$
\pi_{i}(t)+\dot{v}_{i}(t)=r^{i}(t) v_{i}(t)
$$

Free entry into product development in country $i$ implies the following zero-profit condition

$$
v_{i}(t)=w^{i}(t) F^{i}(t)
$$

Capital market clearing in country $i$ requires that domestic savings equal domestic investment, i.e. aggregate asset holdings $A_{i}(t)$ must equal the stock market value of firms $\int_{j=0}^{N^{i}(t)} v_{i}(t) d j=N^{i}(t) v_{i}(t)$. The interest rate $r^{i}(t)$ adjusts such that the capital market in country $i$ clears in every period.

\subsubsection{Balance of Payments}

We require the balance of payments to balance period by period (note that the derivation is identical to the one in the full-trade steady state)

$$
\left[\beta L N_{M}^{R}(t) z_{P}(t)-(1-\beta) L N^{P}(t) \tau z_{P}(t)\right]-\beta L T_{P}=0
$$

where the term in brackets denotes the balance of trade and the second term net transfer payments.

\subsubsection{Steady state}

Still, we consider a steady state in which all variables in both countries grow at the same constant rate $g>0$. This implies that in each country prices, quantities, profits, the interest rate, and the share of labor allocated to production and $\mathrm{R} \& \mathrm{D}$ are constant, as well as the share of exporters in the rich country. Equations (3.13)-(3.22) characterize the steady state. We choose the marginal cost of production for firms in the poor country as the numeraire and set $w^{P}(t) b^{P}(t)=1$. All equations describing the steady 
state are stated in Appendix 7.3.1. In general, the steady state growth rate $g$ and the production share of the poor country $\zeta$ are determined by the intersection of the labor market clearing conditions

$$
\begin{aligned}
(1-\beta) L \theta_{R} & =g(1-\zeta) F^{R}+(1-\zeta) b^{R}(1-\beta) L+\zeta \tau^{2} b^{R}(1-\beta) L+\frac{\tau b^{R} \beta L T}{\frac{F^{P}(g+\rho)}{b^{P} L[\beta+\tau(1-\beta)]}+1} \\
\beta L \theta_{P} & =g \zeta F^{P}+\zeta b^{P} \beta L+\zeta \tau b^{P}(1-\beta) L
\end{aligned}
$$

where we used the balance of payment condition and the zero-profit condition in the poor country to solve for the share of exporting firms in the rich country $\Omega$ as a function of $\zeta$ and $g$. If there is no transfer system, i.e. $T=0$, we prove in Proposition 4 that there exists a unique steady state.

Proposition 4. In the case where $T=0$, a unique steady state with a positive growth rate $g>0$ and production share of the poor country $\zeta>0$ exists if $g(\zeta=0) \rightarrow \infty$ and $g(\zeta=1)>0$ in equation (3.24) and $g(\zeta=1) \rightarrow \infty$ and $g(\zeta=0)>0$ in equation (3.23), and $\theta_{R} \geq \theta_{P}>\tau^{2} b^{R}$ holds so that $\partial g(\zeta) / \partial \zeta>0$ for all $\zeta \in(0,1)$ in (3.23). Otherwise, the steady state features stagnation, i.e. $g=0$.

Proof. The proof follows by the properties of (3.23) and (3.24).

The graphical solution to the steady state looks similar to Figure 3 for the full-trade steady state. Hence, we abstain from depicting the steady state graphically. In the general case, where $T \neq 0$, the analytical study of the steady state is algebraically complex, so that in the following we will study the properties of the full- and part-trade steady state by numerical simulation.

\section{Comparative statics and transitional dynamics}

In this section we discuss how changes in the distribution of income across countries, and a market or education reform in the poor country that makes labor in the domestic research sector more productive affects the trade patterns and the incentives to innovate. We use the example of a market reform to discuss how the global economy adjusts to a new steady state after a change in the poor country's labor productivity in the research sector occurred.

\subsection{A Change in Income Inequality across Countries}

This section discusses the consequences of a change in global, i.e. between-country, inequality for the incentives to innovate and the patterns of international trade. We start our analysis by simulating a full-trade steady state and make regressive transfers, i.e. transfers from the poor country to the rich country, until the economy is in a part-trade steady state. Note, that in this section we compare steady states. We will turn to the transitional dynamics in the next section. 
How inequality affects the steady state in our numerical simulation, where the economy starts out in a full-trade steady state and ends up in a part-trade steady state, is summarized in Result 1 below.

Result 1. An increase in inequality through a regressive transfer has a positive effect on the growth rate $g$, and the terms of trade for the poor country $p$, a negative effect on the production share of the poor country $\zeta$, the share of exporting firms in the rich country $\Omega$, and the consumption share of households in the poor country $n$, and has no effect on the relative wage rate $w$.

In Appendix 7.3.3 we specify the parameter values used in our simulation and show the simulation results in Figures 6-9. The intuition behind Result 1 is the following. As long as the economy is still in a full-trade steady state after the regressive transfer, i.e. $z_{R}<\tau z_{P}$ holds, households in the poor country can still afford to buy one unit of all goods available on the world market. Hence, the incentives to innovate have not changed. In other words, the resource constraints (3.11)-(3.12) are not affected since there is no intensive margin of consumption. Relative prices $z_{R} / z_{P}$, i.e. the terms of trade, increase but as long as $z_{R}<\tau z_{P}$ holds no firm in the rich country has an incentive not to export. However, if the economy is in a part-trade steady state after the regressive transfer, i.e. $z_{R} \geq \tau z_{P}$ holds, households in the poor country are ceteris paribus too poor to afford all goods available on the world market, and relative consumption $n$ falls. Some firms in the rich country have an incentive not to export to the poor country so that $\Omega$ decreases. Hence, in the production sector of the rich country resources are set free that can be reallocated to research and development in the rich country. Innovation incentives in the rich country increase. This implies that more new products are being developed in the rich country than in the poor country such that the production share of the poor country $\zeta$ declines. This absorbs additional resources in the production sector of the rich country, which tends to decrease growth, while at the same time, releases resources from the production sector to the R\&D sector in the poor country, which tends to increase growth. In our simulations, the positive effects on the growth rate $g$ dominate. Alternatively, one could argue as follows. An increase in inequality across countries, ceteris paribus, increases the willingness to pay of households in the rich relative to the poor country. Hence, the price elasticity of demand of households in the rich country decreases so that firms can charge higher markups on marginal costs and earn higher profits from selling to them. At the same time, households in the poor country become more price sensitive so that markups and profits earned from selling to them decrease. As long as the inequality does not increase too much, and the economy remains in a full-trade steady state, these two effects offset each other. Hence, profits and therefore the incentives to innovate are not affected. However, if inequality increases sufficiently, the economy ends up in a part-trade steady state where households in the poor country can no longer afford to buy all products available ( $n$ decreases). In that case, firms that choose not to export can charge higher markups if 
inequality increases, and therefore earn higher profits. Arbitrage in the rich country implies that profits for firms that do export must increase as well so that firms pursuing either strategy earn the same profits in equilibrium. Remember that the (marginal) willingness to pay of households in the poor country increases ceteris paribus as they consume less differentiated products. Hence, the incentives to innovate increase as inequality across countries increases. As inequality increases, less and less firms in the rich country have an incentive to export ( $\Omega$ falls), and due to the home market effect makes relatively more firms locate in the rich country ( $\zeta$ decreases). Note that markups on domestically sold goods are higher than on exported goods since trade costs cannot be passed on to consumers.

As inequality increases the terms of trade $p=z_{R} / z_{P}$ move in favor of the poor country until the economy is in a part-trade steady state when the terms of trade are pinned down by trade $\operatorname{costs} \tau>1$ and therefore constant because the price setting restriction $z_{R}>\tau z_{P}$ is binding. The intuition is straightforward. As households in the rich country become relatively richer they can pay higher prices $z_{R}$ whereas households in the poor country become poorer and can pay lower prices $z_{P}$. Hence, firms located in the poor country get relatively higher prices for their export goods. Remember that as long as the economy is in a full-trade steady state households in the rich and poor country always buy the same consumption basket but households in the rich country pay higher prices for that same basket (firms can fully skim the willingness to pay of households). Hence, a regressive transfer increases (decreases) the willingness to pay of households in the rich (poor) country and therefore increases (decreases) prices, holding the number of differentiated goods purchased constant.

Note that since technologies and population sizes do not change because of a regressive transfer and are still identical across countries, relative wages are always equalized regardless of whether the economy is in a full- or part-trade steady state (see Appendix 7.2.3 and 7.3.2).

In sum, an increase in (lifetime) income inequality across countries leads to an increase in the world growth rate $g$, and at the same time, to a decrease in the number of differentiated goods that are traded between countries (extensive margin of trade). In other words, the extensive margin of trade depends negatively on inequality across countries. Among others, Bernasconi (2011) finds evidence for the extensive (and intensive) margin of trade, i.e. the higher the overlap of the income distributions of two countries, the more product categories (extensive margin) they trade with each other. To the best of our knowledge there is no empirical study that looks at the effect of cross-country income inequality on (global) economic growth. The empirical studies we are aware of analyze the relationship between income inequality within countries and growth. The results from these studies are inconclusive. Some, like Barro (2000), find a negative relationship between income inequality within countries and growth for poor countries and a positive relationship for rich countries. Others, like Perotti (1996), find a negative relationship. 


\subsection{A Change in Technology}

In this section, we discuss the effects of a decline in the labor requirement to create a new product in the poor country $F^{P}$. One could think of this case as a market reform (i.e. easier access to product and/or financial markets) or an education reform in the poor country or region that makes labor in the research and development sector (relatively) more productive.

The results of our numerical simulation are summarized below

Result 2. An increase in labor productivity in $R \& D$ in the poor country, i.e. a decrease in $F^{P}$, leads to an endogenous decrease in inequality across countries. At high levels of $F^{P}$, such that the economy is in a part-trade equilibrium, a reduction of $F^{P}$ leads to a decrease in the growth rate $g$, whereas at low levels of $F^{P}$, such that the economy is in a full-trade equilibrium, a reduction of $F^{P}$ leads to an increase in $\mathrm{g}$. The production share of the poor country $\zeta$ increases whereas the relative wage rate and the terms of trade decrease as $F^{P}$ falls.

The parameter values used in our simulation and Figures 9-12 that show the simulated effects of a decline in $F^{P}$ are given in Appendix 7.3.4. There are two effects driving this result. First, if labor is more productive in $R \& D$ in the poor country the cost of innovation ceteris paribus falls so that the incentives to innovate increase. Second, as labor (in R\&D) becomes more productive in the poor country inequality across countries (endogenously) decreases. This has ceteris paribus a negative effect on the incentives to innovate because households in the poor country can afford to buy more products, which absorbs more resources in the production sector of the rich country (so that less resources are available for R\&D). In a part-trade equilibrium the second effect outweighs the first effect so that an increase in the labor productivity in the R\&D sector of the poor country has a negative effect on the growth rate $g$. As long as the economy is in a full-trade equilibrium, only the first effect is present because households in the poor country consume all goods available inequality has no effect on the incentives to innovate. Hence, the increase in labor productivity $1 / F^{P}$ has a positive effect on the growth rate $g$.

Since the innovation cost ceteris paribus decreases as $F^{P}$ falls, relatively more new products are developed in the poor country so that $\zeta$ increases. As $F^{P}$ falls and labor in the poor country becomes relatively more productive the relative wage rate $w^{R}(t) / w^{P}(t)$ falls. Furthermore, as households in the rich country become relatively less rich, i.e. inequality across countries decreases, the terms of trade fall.

In sum, we have a kind of "U-shape" relationship between labor productivity in R\&D of the poor country, which we can think of as a measure of (market) development in the poor country or region, and the (world) growth rate $g$. 


\subsection{Transitional Dynamics}

We illustrate the transitional dynamics with the example of a change in technology in the poor country discussed in the previous section. To this end, we discuss the transition for the case of no transfer system, i.e. $T(t)=0$ for all $t$. This is convenient since it allows us to solve analytically and graphically for the transitional dynamics. In the full-trade equilibrium transitional dynamics are governed by equations (3.3)-(3.10) and in the part-trade equilibrium by equations (3.13)-(3.22). The labor market clearing equations (3.5)-(3.6) for the full-trade equilibrium and (3.16)-(3.17) together with the balance of payments (3.22) for the part-trade equilibrium describe a system of autonomous and homogeneous linear first-order differential equations we can write as follows

$$
\begin{aligned}
& \dot{N}^{R}(t)=\Phi_{k}^{R} N^{R}(t)+\Psi_{k}^{R} N^{P}(t) \\
& \dot{N}^{P}(t)=\Phi_{k}^{P} N^{P}(t)+\Psi_{k}^{P} N^{R}(t)
\end{aligned}
$$

for $k=\{$ full,part $\}$. The definition of the constants $\Phi_{k}^{R}, \Psi_{k}^{R}, \Phi_{k}^{P}$ and $\Psi_{k}^{P}$, and the analytical solution to this system of differential equations are given in Appendix 7.4. Here, we analyze the transitional dynamics with the help of the phase diagram. In the steady state, the set of differentiated goods in both countries grows at a constant common rate $g>0$. For notational convenience we drop the subscript $k$. From equation (4.1) follows $\bar{m} \equiv\left(g-\Phi^{R}\right) / \Psi^{R}>0$ where $\bar{m} \equiv N^{P}(t) / N^{R}(t)>0$ in steady state. Note that parameter values must be such that $m(t)>0$ for all $t$. Hence, we see that

$$
\frac{\dot{N}^{R}(t)}{N^{R}(t)}\left\{\begin{array}{lll}
>g, & \text { if } & m(t)>\bar{m} \\
=g, & \text { if } & m(t)=\bar{m} \\
<g, & \text { if } & m(t)<\bar{m}
\end{array}\right.
$$

Similarly, from equation (4.2) follows $\bar{m} \equiv \Psi^{P} /\left(g-\Phi^{P}\right)>0$. Therefore, we observe that

$$
\frac{\dot{N}^{P}(t)}{N^{P}(t)}\left\{\begin{array}{lll}
<g, & \text { if } & m(t)>\bar{m} \\
=g, & \text { if } & m(t)=\bar{m} \\
>g, & \text { if } & m(t)<\bar{m}
\end{array}\right.
$$

Obviously, the steady state growth rate $g$ is determined by $\left(g-\Phi^{R}\right)\left(g-\Phi^{P}\right)=\Psi^{R} \Psi^{P}$. In sum, if $m(t)<\bar{m}$, the set of differentiated goods in the rich country $N^{R}(t)$ grows at a lower rate than the steady state growth rate $g$ while the set of differentiated goods in the poor country $N^{P}(t)$ grows at a higher rate than $g$. Hence, the ratio $m(t)=N^{P}(t) / N^{R}(t)$ converges asymptotically to its steady state 
value $\bar{m}$, and vice versa, if $m(t)>\bar{m}$. The balance of payments condition in the full-trade steady state defines a critical level of $\widetilde{m} \equiv \beta /(1-\beta) \tau>0$, where $\widetilde{m}$ satisfies $z_{R} / z_{P}=\beta /(1-\beta) \widetilde{m}=\tau$. Hence, for $m(t)>\widetilde{m}$ the dynamics of the economy are governed by the dynamics in a full-trade equilibrium, and vice versa.

Now, we can illustrate the transitional dynamics with the help of the example discussed in Section 4.2. In Figure 4 we analyze the effect of an exogenous decrease in the labor requirement to develop new products in the poor country $F^{P}$, i.e. labor in the $\mathrm{R} \& \mathrm{D}$ sector becomes more productive, which shocks the economy out of its part-trade steady state. We assume that the new level of $F^{P}$ sustains a fulltrade steady state with a higher ratio of firms located in the poor to the rich country $m(t)$. During the transition from the part- to the full-trade steady state the ratio $\bar{m}_{\text {part }}<\bar{m}_{\text {full }}$ monotonically increases until it reaches $\bar{m}_{\text {full }}$. As long as $m(t) \leq \widetilde{m}<\bar{m}_{\text {full }}$ the economy is in a part-trade equilibrium, and as $\widetilde{m}<m(t) \leq \bar{m}_{\text {full }}$ the economy is in a full-trade equilibrium. Hence, during the transition households in the poor country must invest (i.e. save) relatively more in the development of new products than households in the rich country, i.e. aggregate consumption expenditures of households in the poor country $E_{P}(t)=\beta L e_{P}(t)$ must grow at a lower rate during transition than consumption expenditures of households in the rich country $E_{R}(t)=(1-\beta) L e_{R}(t)$. In other words, relatively more resources are temporarily invested in $\mathrm{R} \& \mathrm{D}$ in the poor relative to the rich country. Regardless of whether the economy ends up in full- or part-trade steady state with a higher or lower (world) growth rate, a market reform in the poor country triggers temporarily more investment in $R \& D$ in the poor country.

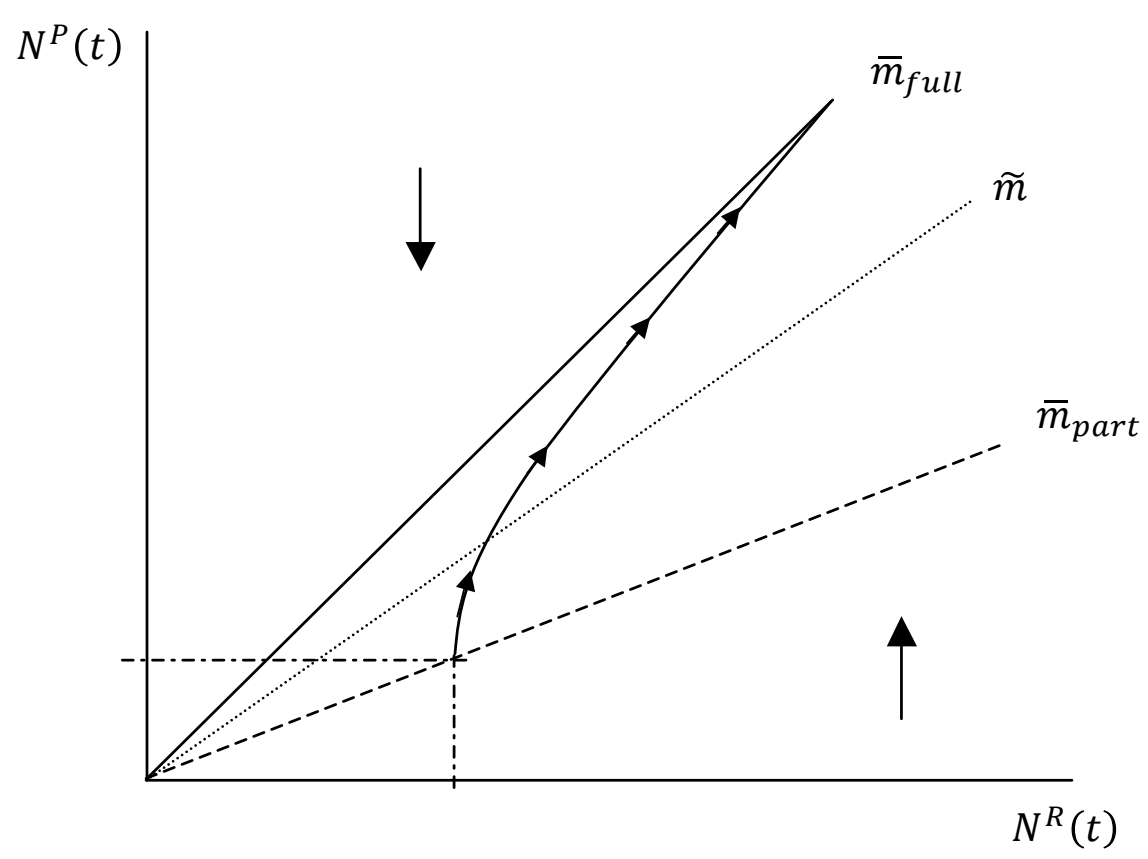

Figure 4: Phase diagram: A drop in $F^{P}$ 


\section{$5 \quad$ Applications and extensions}

In this section we discuss applications in the form of policy changes and its welfare consequences as well as extensions like alternate assumptions about knowledge spillovers, preferences and the distribution of income within a country. Instead of working out general cases we concentrate on some special cases that highlight interesting points. All of the issues addressed in this section arise because we introduce non-homothetic preferences, and therefore cannot be addressed in Grossman and Helpman's (1991) standard model.

\subsection{Policy}

\subsubsection{Intellectual property rights}

We use our model to study how the design of intellectual property rights determines trade patterns and the incentives to innovate. So far we have assumed that there is international exhaustion of patents, in other words, parallel imports cannot be legally prevented. Now suppose that policymakers in both countries simultaneously choose to introduce national exhaustion of patents so that parallel imports can be legally prevented ${ }^{3}$. In that case the price setting restriction is never binding regardless of the level of inequality across countries or trade costs. Hence, the economy is always in a full-trade equilibrium. Since monopolistic firms can fully price discriminate across countries it is never a dominant strategy for a firm located in the rich country to sell exclusively on its domestic market as long as households in the poor country are not too poor, i.e. $z_{P} \geq \tau \omega^{R} b^{R}$. This implies that more resources are absorbed in production (relative to a part-trade equilibrium under international exhaustion) so that less resources can be allocated to research and development. In sum, we can conclude that national exhaustion of patents would depress growth but would encourage international trade at the extensive margin. Households in the poor country suffer a dynamic loss (incomes grow at a lower $g$ ) but experience a static gain (consume a larger share $n$ of products) whereas households in the rich country only suffer a dynamic loss (lower $g$ ). Since households in the rich country suffer only losses they would almost surely favor international exhaustion of patents. Whether households in the poor country favor international or national exhaustion of patents depends on their time preference rate, i.e. how much they discount future losses against current gains.

The design of property rights and its effects on the incentives to innovate have been a hot topic for some time in the public (e.g. trade-related aspects of intellectual property rights TRIPS) and academic

\footnotetext{
${ }^{3}$ Suppose that the rich country does not allow parallel imports but the poor country does. This implies that the price setting restriction is never binding, and all firms located in the rich country always export. Consider the opposite case where the rich country allows parallel imports but the poor country does not. In that case, some firms in the rich country might have an incentive not to export. Note that in both cases, the policy of the poor country does not affect the incentives to export of firms in the rich country.
} 
debate. This is especially true for pharmaceutical products in the US where prices of identical drugs differ substantially from those in Canada or Mexico. A recent example from the academic literature is Grossman and Lai (2008) who find that the innovation rate is faster in a world with international exhaustion of patents (compared to national exhaustion). In their model, parallel imports are induced by different national price controls, in contrast to our model where the extent of income inequality across countries induces parallel imports. Grossman and Lai (2008) argue that a switch from national to international exhaustion of patents changes innovation incentives because the government follows different motives in its price regulation with and without parallel imports.

\subsubsection{Trade policy}

Our model can be applied to study the effects of trade liberalization in the form of a reduction of tariffs induced for example by the General Agreement on Tariffs and Trade (GATT). Suppose that such a policy liberalizing trade is put in place. We can interpret a decrease in trade $\operatorname{costs} \tau>1$ as a reduction in tariffs. Note that $\tau$ captures all possible barriers to trade in goods, e.g. efficiency of the transportation sector, or non-tariff barriers to trade. Note that with zero-one preferences trade costs are borne by firms whereas with CES preferences firms pass them on to consumers. A decrease in trade costs increases profits and therefore the incentives to innovate, ceteris paribus. If the fall in trade costs implies that the price setting restriction for firms becomes binding the economy ends up in a part-trade steady state. We know that ceteris paribus in a part-trade steady state the incentives to innovate are higher than in a full-trade steady state. The alternative argument is that a decrease in trade costs releases resources from the production sector that can be allocated to research and development (in both countries). If trade costs fall sufficiently so that the economy ends up in a part-trade equilibrium, further resources are released from the production sector since households in the poor country can no longer afford to consume all goods produced in the rich country. Either way, the growth rate of the global economy increases if trade costs fall. Hence, we conclude that trade liberalization has a positive effect on the growth rate and might have a negative effect on the extensive margin of trade. In Section 5.2 we discuss the welfare consequences of a trade liberalization. Our results are in line with the empirical evidence that suggests a negative relationship between trade restrictions and economic growth. A critical survey of the empirical literature can be found in Rodriguez and Rodrik (2000). In contrast, in the standard model with CES preferences trade costs have no effect on the incentives to innovate because they are passed on to consumers (they change prices and quantities sold such that profits remain constant). 


\subsection{Welfare}

We focus our welfare analysis on the effect of a trade liberalization on relative welfare levels. The advantage of that analysis is that we can shut down transfers, i.e. $T(t)=0$ for all $t$, and trace the transitional dynamics analytically. First, in equilibrium the difference in welfare (indirect utility) levels between households in the rich and the poor country, i.e. $\Delta V(0) \equiv V_{R}(0)-V_{P}(0)$, is given by

$$
\Delta V(0)=\int_{0}^{\infty} e^{-\rho t} \log \frac{N_{R}(t)}{N_{P}(t)} d t
$$

Note that in a full-trade equilibrium $N_{R}(t)=N_{P}(t)=N(t)$ for all $t$ whereas in a part trade equilibrium $N_{P}(t)<N_{R}(t)$ for all $t$. In order to analyze the effect of a change in trade policy on welfare consider a decrease of $\tau$, as discussed in Section 5.1.2, from a level that sustains a full-trade equilibrium to one that sustains a part-trade equilibrium. First, note that there is a critical $\widetilde{m}>0$, where $(1-\beta) \widetilde{m} / \beta \equiv \tau_{\text {crit }}$ and $\tau_{\text {crit }} \equiv z_{R} / z_{P}$, at which point the economy switches from a full- to a part-trade equilibrium. First, in a steady state with high trade costs $\tau$ we have a relatively high $\bar{m}=N^{P}(t) / N^{R}(t)>\widetilde{m}$ whereas in a steady state with low trade costs $\bar{m}<\widetilde{m}$ is also low. In a part-trade equilibrium relatively more firms enter in the rich than in the poor country because in the rich country resources are released from the production sector that can be allocated to the research sector due to the fact that households in the poor country can no longer afford to purchase all products produced in the rich country. Hence, during the transition $m(t)$ falls from a level above $\widetilde{m}$ to one below. As long as $m(t)>\widetilde{m}$, the economy is in a full-trade equilibrium, and $\Delta V(0)$ is equal to zero since $N_{R}(t)=N_{P}(t)$. Eventually, as $m(t)<\widetilde{m}$ the economy switches to a part-trade equilibrium, and the difference in welfare can be written as (using the balance of payments condition in the part-trade equilibrium)

$$
\Delta V(0)=\int_{0}^{\infty} e^{-\rho t} \log \xi\left(1+\frac{1}{m(t)}\right) d t>0
$$

where $\xi \equiv \beta /[\beta+\tau(1-\beta)]$. We know that $m(t)$ falls until it has reached its new steady state value $\bar{m}<\tilde{m}$. This implies that $\Delta V(0)$ becomes positive as the economy switches from a full- to a part-trade equilibrium, increases during the transition until the economy has reached the new steady state, and stays constant at a positive value from then on. Hence, we can conclude that the households in the poor country unambiguously loose relative to the households in the rich country from a trade liberalization in the form of a decrease in trade costs $\tau$. Intuitively, households across countries share a common growth rate in and out of the steady state (implied through the balance of payments condition) of their corresponding consumption sets (i.e. indirect utility) regardless of whether the economy is in a fullor part-trade equilibrium, and differ only with respect to the sizes of their consumption sets $N_{i}$ if the 
economy is in a part-trade equilibrium ${ }^{4}$. Therefore, households in the poor country only experience a relative loss in the sense that the set of goods they consume $N_{P}(t)$ falls relative to the set of goods consumed by households in the rich country $N_{R}(t)$ as the economy moves from a full- to a part-trade equilibrium. In sum, households in the poor country might be opposed to a trade liberalization if trade costs decrease so much that firms can no longer perfectly price discriminate across countries and some firms in the rich country decide to no longer serve the poor country.

\subsection{Knowledge spillovers: learning-by-importing}

Remember that Coe and Helpman's (1995) estimates suggest that foreign R\&D has a more beneficial effect on domestic productivity the more open an economy is to foreign trade. We pick this idea up and look at the case when intertemporal knowledge spillovers in research and development only originate from domestically produced goods and imported goods. Hence, in our model the extent of international knowledge spillovers is endogenously determined by trade patterns, which in turn are determined by income inequality across countries. Technology in country $i=\{R, P\}$ is now as follows. To develop a new product $F^{i}(t)=F / N_{i}(t)$ units of labor are required, and to produce 1 unit of output it needs $b(t)=b / N(t)$ units of labor. Note that for simplicity we assume that technology is symmetric across countries except for the extent of international knowledge spillovers in R\&D. Furthermore, we assume that each country's population size is given by $L$. Suppose that inequality across countries is low for a given level of trade costs (or that for a given level of inequality trade costs are high) so that the economy is in a full-trade equilibrium, i.e. $N_{R}(t)=N_{P}(t)=N(t)$. Both countries import all goods produced in the other country so that there are perfect international knowledge spillovers. In that case, the world growth rate in the steady state is given by

$$
g=\frac{1}{F}\left[\theta_{R}+\theta_{P}-(1+\tau) b\right] L>0 \Leftrightarrow \theta_{R}+\theta_{P}>(1+\tau) b
$$

Now, consider the case where inequality across countries is high (or trade costs are low) so that the economy is in a part-trade equilibrium. Hence, $N_{P}(t)=N^{P}(t)+N_{M}^{R}(t)<N_{R}(t)=N(t)$ so that $N_{P}(t) / N(t)=\zeta+\Omega(1-\zeta)$. To solve for the steady state, we only have to modify the resource constraint of the poor country as follows

$$
\beta L \theta_{P}=g \frac{\zeta}{\zeta+\Omega(1-\zeta)} F+\zeta(1+\tau) b L
$$

\footnotetext{
${ }^{4}$ However, note that consumption expenditures evolve differently across countries during the transition. Since $m=$ $N^{P} / N^{R}$ falls over time it must be that aggregate consumption expenditures in the rich country grow at a lower rate than in the poor country.
} 
Due to our choice of numeraire, i.e. $w^{P}(t) b^{P}(t)=1$, the rest of the equations for the part-trade equilibrium in Appendix 7.3.1 continue to apply. First, note that if there are no transfers $T=0$ the growth rate is determined by the resource constraints in the poor and rich countries. In the general case, with $T \neq 0$ one can show with the help of numerical simulations that an increase in inequality across countries through a regressive transfer increases the steady state growth rate $g$. Intuitively, if households in the poor country become even poorer they can afford to purchase less products as before. Hence, labor in the $\mathrm{R} \& \mathrm{D}$ sector of the poor country becomes ceteris paribus less productive, which increases the cost of innovation in the poor country. At the same time, households in the rich country become even richer, which increases the incentives to innovate in the rich country. In our simulations, the positive effect on growth in the rich country still dominates so that the (global) growth rate $g$ increases.

Limit case: no learning-by-importing Note that if there are no international knowledge spillovers, there might be uneven growth across countries. In the full-trade steady state, the rich, respectively, poor country grows at the rate

$$
\begin{aligned}
g^{R} & =\frac{1}{F^{R}}\left[(1-\beta) \theta_{R}-[(1-\beta)+\tau \beta] b^{R}\right] L \Leftrightarrow(1-\beta) \theta_{R}>[(1-\beta)+\tau \beta] b^{R} \\
g^{P} & =\frac{1}{F^{P}}\left[\beta \theta_{P}-[\beta+\tau(1-\beta)] b^{P}\right] L \Leftrightarrow \beta \theta_{P}>[\beta+\tau(1-\beta)] b^{P}
\end{aligned}
$$

In the case, where technology is symmetric, $g^{R}>g^{P}$ if and only if $(1-\beta) \theta_{R}-\beta \theta_{P}>1-\tau$. This implies that if all households have the same endowments with efficiency units of labor $\theta_{R}=\theta_{P}=\theta$ a sufficient condition for $g^{R}>g^{P}$ is $\beta<0.5$. In other words, the relatively larger country in terms of population size grows at the higher rate (due to the home market effect and scale effects). Furthermore, if $\beta=0.5$ a necessary and sufficient condition for $g^{R}>g^{P}$ is $\theta_{R}>\theta_{P}$. Intuitively, the country with the relatively higher labor endowment grows at the higher rate due to the increasing-returns-to-scale technology. We see that the distribution of income across countries (i.e. a regressive transfer) still has no effect on the incentives to innovate.

In the part-trade steady state, the balance of payments requires that $\zeta=N^{P}(t) / N(t)$ is constant. However, this implies that the growth rate in both countries must be the same, i.e. $g^{R}=g^{P}=g$. Hence, the (world) growth rate $g$ is determined by the resource constraint in the poor country

$$
g=\frac{1}{F^{P}}\left[\beta \theta_{P}-[\beta+\tau(1-\beta)] b^{P}\right] L \Leftrightarrow \beta \theta_{P}>[\beta+\tau(1-\beta)] b^{P}
$$

The resource constraint in the rich country $(1-\beta) L \theta_{R}=g F^{R}+b^{R}(1-\beta) L+\Omega \tau b^{R} \beta L$ then pins down the 
number of firms located in the rich country that export $\Omega$. In other words, the number of exporting firms in the rich country adjusts such that given the world growth rate determined in the poor country, the labor market in the rich country clears. Apparently, a regressive transfer, which increases inequality, has now no effect on the growth rate $g$. A regressive transfer only results in an adjustment of the balance of payments, i.e. the willingness to pay of households in the poor country $z_{P}$ decreases and/or the production share of the poor country $\zeta$ increases, such that $\Omega$ remains consistent with labor market clearing. We conclude that in the part-trade steady state the incentives to innovate are determined by technology and endowments in the two countries and are independent of the distribution of income across countries if there are no international knowledge spillovers. However, note that inequality across countries still has an effect on innovation incentives and trade in the sense that if inequality increases sufficiently the economy switches from a full- to a part-trade steady state. This implies that a sufficiently high increase in inequality might now lead to a decrease in the average growth rate if and only if $g^{R}>g^{P}$. We further get convergence in growth rates but divergence in consumption levels.

\subsection{Within-country inequality}

We illustrate the effect of within-country inequality (abstracting from inequality across countries) on trade patterns and the incentives to innovate with a simple example.

Consider the following case. There are two countries with equal population sizes. In country $R$ one half of the households owns more than half of the wealth in the country, and the other half owns the rest. In country $P$ all households own an equal share in country $P$ 's wealth. Suppose that the average per capita income is the same in both countries. Hence, there is inequality within country $R$ but no inequality across countries. We assume that the rich in country $R$ are wealthier than the households in country $P$, which are in turn wealthier than the poor in country $R$. Inequality within country $R$ generates exclusion since by assumption there are no trade cost within a country, we assume that firms cannot distinguish between rich and poor households within country $R$ or that storage of such information is prohibitively costly.

First, suppose that inequality within country $R$ is low for a given level of trade $\operatorname{costs} \tau$ (or that $\tau$ is high for a given level of within-country inequality). In particular, assume that (i) the willingness to pay of households in country $P$ falls short of trade costs times the willingness to pay of the poor in country $R$, and (ii) that the willingness to pay of rich households in country $R$ falls short of trade costs times the willingness to pay of households in country $P$. Assumption $(i)$ implies that firms located in country $R$ that sell to all households in both countries can perfectly price discriminate across countries (but not within country $R$ ), and assumption (ii) implies that firms that sell exclusively to the rich in 
country $R$ and to households in country $P$ can also perfectly price discriminate across countries. Hence, assumptions $(i)$ and $(i i)$ imply that no firm has an incentive not to export to country $P$, i.e. to sell only to the rich in country $R$. Hence, an equilibrium emerges where all goods available are traded.

Second, suppose that inequality within country $R$ is high for a given level of trade cost $\tau$ (or that $\tau$ is low for a given level of within-country inequality). Assume that $(i)$ continues to hold but that $(i i)$ is no longer true. This implies that firms located in country $R$ that export can no longer perfectly price discriminate between rich households in country $R$ and households in country $P$. This induces some firms located in country $R$ not to export to country $P$. Hence, not all goods available are traded in equilibrium.

We know from our previous analysis that in an equilibrium where all goods produced in country $R$ are traded more resources in that country need to be allocated to the production sector compared to an equilibrium where only part of all goods produced there is traded. This implies that in the second case, where inequality within country $R$ is high, more resources are available for research and development. Hence, we would expect that the world economy grows at a higher rate if within-country inequality is high compared to when it is low.

\subsection{Quadratic Preferences}

We briefly discuss the case where households can adjust their consumption along the extensive and intensive margin ${ }^{5}$. The households' (quasi-homothetic) utility function takes the following form

$$
u\left(\{c(j, t)\}_{j=0}^{\infty}\right)=\int_{j=0}^{\infty}\left(s c(j, t)-\frac{1}{2} c(j, t)^{2}\right) d j
$$

where $s>0$ denotes a saturation level. The utility function has the following (standard) properties, $u^{\prime}(\cdot)=s-c(j, t)>0, u^{\prime \prime}(c(j, t))=-1<0$, and $\lim _{c(j, t) \rightarrow 0} u^{\prime}(\cdot)=s<\infty$, which implies that marginal utility is bounded from above. Therefore, non-negativity constraints $c(j, t) \geq 0$ might become binding for some $j$ 's. Rich households consume not only a larger set of goods but also a larger quantity of each good than poor households. With quadratic preferences households have a choice about how many different goods they consume (extensive margin) as well as about how much of each good they consume (intensive margin).

We restrict our discussion to the effect of income inequality across countries on trade patterns and the incentives to innovate. Again, the analytical analysis of the equilibrium is complex. Therefore, we simulate the comparative statics results. We make the same experiment as in Section 4.1, and simulate a change in (lifetime) income inequality across countries by making regressive transfers, starting out in

\footnotetext{
${ }^{5}$ The appendix containing the formal model with quadratic preferences and all simulations is available upon request from the author.
} 
a full-trade steady state, and ending up in a part-trade steady state. In the appendix we show that with quadratic preferences non-negativity constraints may be binding. Hence, a part-trade equilibrium might emerge if households in the poor country are very poor. First, we summarize the results from our simulations in

Result 3. An increase in inequality through a regressive transfer has a positive effect on the growth rate, the terms of trade for the poor country, and a negative effect on the production share of the poor country, the share of exporting firms, and the consumption share of households in the poor country.

Next, we give an intuition for Result 3, and compare it with Result 1 of our baseline model with zero-one preferences. Since the results and their intuition are similar to the case of zero-one preferences we will keep the discussion relatively short. Given that the rich consume all goods available they can only increase their consumption by increasing the amount of each good they purchase. However, since they are satiated at one point, the price elasticity of demand for those goods decreases. Hence, markups rise, and the incentive to innovate tends to increase. At the same time, households in the poor country become poorer and decrease the consumption of each good they purchase, ceteris paribus. The price elasticity of demand tends to increase, markups to fall, so that the incentive to innovate tends to decrease. Note that the economy is in a full-trade equilibrium as long as households in the poor country become not too poor such that they also decrease the number of goods they purchase relative to the number of goods that are available on the market, else the economy is in a part-trade equilibrium. In both cases, our simulations show that the effect of the households in the rich country on the incentives to innovate dominate, so that we see more innovation in a steady state with higher inequality across countries. This effect is even stronger in a part-trade equilibrium when households in the rich country are very rich, and pay very high markups. The intuition for the movement of the terms of trade in favor of the poor country, for the decrease in the share of exporting firms in the rich country, and the fall in the production share of the poor country is the same as in our baseline model (see discussion in Section 4.1).

It is worth noting two things that are different to the baseline model. First, since there is an intensive margin of consumption the incentives to innovate in the full-trade equilibrium change as inequality across countries changes. Second, the extensive and intensive margin (i.e. trade volume) is higher in a full-trade equilibrium than in a part-trade equilibrium, which is in line with the empirical evidence from Bernasconi (2011).

In sum, the introduction of quadratic preferences does not change the basic results and intuition of the baseline model. The more similar countries are the higher the extensive and intensive margins of trade, and the lower the incentives to innovate. 


\section{Conclusion}

We look at the consequences of inequality in incomes across countries on the patterns of trade between countries, and the incentives to innovate in the world economy. To this end, we introduce non-homothetic preferences in the standard model of Grossman and Helpman (1991). We show that if income inequality across countries is high, some firms located in the rich country have an incentive to sell exclusively in the domestic market. In order to circumvent the threat of parallel imports and be able to charge high prices they choose to forgo a larger market. At the same time, this means that not all goods produced in the world economy are traded. Since households in the poor country cannot afford to buy all goods produced in the rich country, relatively more resources in the rich country can be allocated to research and development. In sum, at high levels of inequality across countries the extensive margin of trade is low whereas the incentives to innovate are high.

We apply the model to interesting questions that arise in an international context that cannot be addressed in the standard model with CES preferences, and discuss various extensions. First, we apply the model to the question of intellectual property rights in an international context. We show that households in the rich and poor country might not see eye to eye about the design of intellectual property rights. Whether they agree or disagree depends crucially on how much households in the poor country weigh future losses in consumption against present gains. Second, we take a closer look at trade policy, and argue that a reduction in tariffs might increase the incentives to innovate but decrease the extensive margin of trade. Such a change in trade policy might make households in the poor country unambiguously worse off relative to households in the rich country if tariffs fall sufficiently such that the economy moves from a full- to a part-trade equilibrium. We extend the model by making the degree of international knowledge spillovers endogenous. In particular, we assume that knowledge spillovers in the research sector depend on the set of products consumed in a given country. This implies that firms benefit only from knowledge created abroad if these products are imported. We show that the results from the baseline model are robust, i.e. inequality across countries still leads to an increase in the growth rate and a decrease in the extensive margin of trade. We also consider an extreme case by shutting down international knowledge spillovers completely. We show that countries grow at different rates in a full-trade equilibrium, and converge to a common growth rate, which is equal to the growth rate of the poor country, in a part-trade equilibrium. In this limit case an increase in inequality might lead to a decrease in the average growth rate in the economy as well as the extensive margin of trade. We further argue with the help of a simple example that an increase in inequality in the rich country can lead to an increase in the growth rate since it induces some firms located in the unequal rich country not to serve the foreign market and sell exclusively to the wealthy in their domestic country, which 
releases resources for research. Last, we show that the relationship between inequality, trade patterns, and the growth rate is robust to the introduction of preferences where households have a choice along the extensive and intensive margin of consumption.

Our model provides a framework that can be adapted to cover various issues in an international economy. For example Foellmi et al. (2012) analyze a North-South model where the North innovates new products, which the South imitates at random. In their model product cycles like Vernon (1966) described emerge and are shaped by the structure of the demand side. Furthermore, the model could also be applied to gain further insight into the role of the market size, i.e. the structure of the demand side within and across countries, as a determinant of foreign direct investment (FDI). We would hypothesize that countries which have a large mass market attract relatively more FDI. In particular, firms that serve a mass market at low prices abroad (e.g. they sell necessities to the masses) choose FDI over exports whereas firms that serve only a small part of the market at high prices (e.g. they cater to the luxurious needs of the rich) choose exports over FDI in a setup with a proximity-concentration trade-off.

\section{References}

Acemoglu, Daron. Introduction to Modern Economic Growth. Princeton, NJ: Princeton University Press, 2009.

Barro, Robert J. "Inequality and Growth in a Panel of Countries." Journal of Economic Growth, 2000, 5(1), pp. 5-32.

Bernasconi, Claudia. "Income Similarity and Bilateral Trade Flows." Working Paper, 2011.

Burenstam-Linder, Staffan. An Essay on Trade and Transformation. Uppsala: Almqvist \& Wicksells, 1961 .

Coe, David T. and Helpman, Elhanan. "International R\&D spillovers." European Economic Review, 1995, 39(5), pp. 859-87.

The Economist. "A grey market." The Economist print edition, December, 3, 1998.

Foellmi, Reto and Zweimüller, Josef. "Income Distribution and Demand-Induced Innovations." Review of Economic Studies, 2006, 73(4), pp. 941-60.

Foellmi, Reto, Hanslin, Sandra and Kohler, Andreas. "A Dynamic North-South Model of Demand-Induced Product Cycles." Working Paper, 2012.

Foellmi, Reto, Hepenstrick, Christian and Zweimüller, Josef. "Non-homothetic preferences, parallel imports and the extensive margin of trade." CEPR Discussion Papers, 2010, 7939.

Grossman, Gene M. and Helpman, Elhanan. Innovation and Growth in the Global Economy. Cambridge, Mass.: MIT Press, 1991. 
Grossman, Gene M. and Lai, Edwin L.-C. "Parallel imports and price controls." RAND Journal of Economics, 2008, 39(2), pp. 378-402.

KPMG/AGMA. "KPMG/AGMA Survey Projects Global "Gray Market" of USD 58 Billion for Information Technology." Study in Cooperation with the Anti-gray Market Allience, 2008.

Maskus, Keith E. and Chen, Yongmin. "Vertical Price Control and Parallel Imports: Theory and Evidence." Review of International Economics, 2004, 12(4), pp. 551-70.

Markusen, James R. "Putting Per-Capita Income Back into Trade Theory." NBER Working Papers, $2010,15903$.

Matsuyama, Kiminori. "A Ricardian Model with a Continuum of Goods under Nonhomothetic

Preferences: Demand Complementarities, Income Distribution, and North-South Trade." Journal of Political Economy, 2000, 108(6), pp. 1093-1120.

Mitra, Devashish and Trindade, Vitor. "Inequality and Trade." The Canadian Journal of Economics/Revue canadienne d'Economique, 2005, 38(4), pp. 1253-71.

Perotti, Roberto. "Growth, Income Distribution, and Democracy: What the Data Say." Journal of Economic Growth, 1996, 1(2), pp. 149-87.

Ray, Debraj. Development Economics. Princeton, NJ: Princeton University Press, 1998.

Rodriguez, Francisco and Rodrik, Dani. "Trade Policy and Economic Growth: A Skeptic's Guide to the Cross-National Evidence." NBER Macroeconomics Annual, 2000, 15, pp. 261-325.

Romer, Paul M. "Endogenous Technological Change." Journal of Political Economy, 1990, 98(5), pp. 71-102.

Simonovska, Ina. "Income Differences and Prices of Tradables." NBER Working Paper Series, 2010, 16233.

Tirole, Jean. The Theory of Industrial Organization. Cambridge, Mass.: MIT Press, 1988.

\section{Appendix}

\subsection{Measuring inequality}

We construct the Gini coefficient from the Lorenz curve shown in Figure 5 below in the following way (see Ray, 1998). The Gini coefficient $G$ is the ratio of the area between the Lorenz curve and the line of perfect equality (shaded area $\mathrm{ABD}$ ) to the area of the triangle below the 45 degree line (area $\mathrm{ABC}$ ), i.e. $G=$ Area $\mathrm{ABD} /$ Area $\mathrm{ABC}$. In Figure 5, we denote the poor country's share of aggregate lifetime 
income in the steady state by

$$
\frac{Y_{P}(t)}{Y(t)}=\frac{1}{1+\left(\frac{1-\beta}{\beta}\right) \frac{y_{R}(t)}{y_{P}(t)}}
$$

where $y_{R}(t) / y_{P}(t)$ denotes relative lifetime incomes in per capita terms in the steady state. Relative lifetime incomes in per capita terms can be written in the steady state as

$$
\frac{y_{R}(t)}{y_{P}(t)}=\frac{w^{R}(t) \theta_{R}+\rho a_{R}(t)-T_{R}(t)}{w^{P}(t) \theta_{P}+\rho a_{P}(t)+T_{P}(t)}
$$

where $w^{i}(t)$ and $r^{i}(t)$ denote the wage, respectively, the interest rate in country $i$. Obviously, if the poor country's income share $Y_{P}(t) / Y(t)$ equals its population share $\beta$ the Lorenz curve lies on the 45 degree line of perfect equality, and the Gini coefficient is zero.

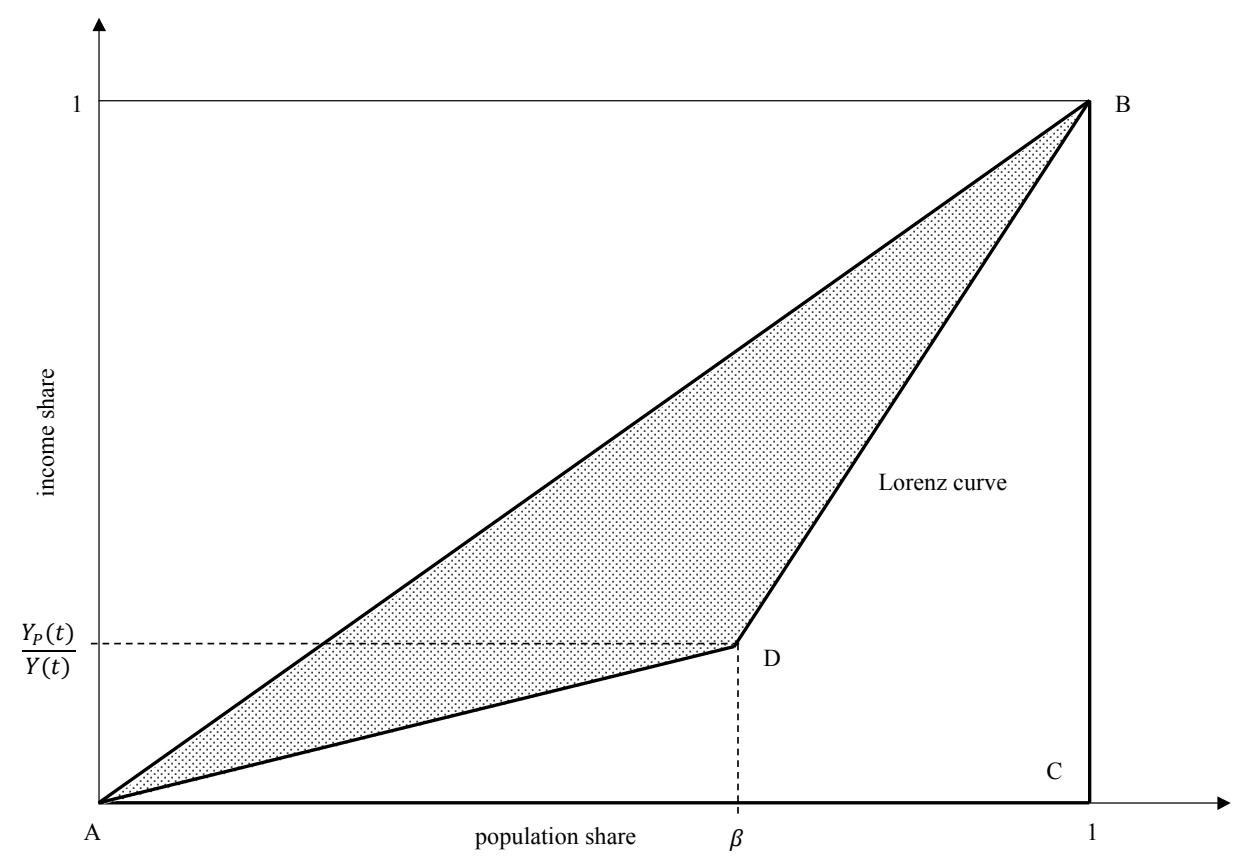

Figure 5: Lorenz curve

\subsection{Full-trade Equilibrium}

\subsubsection{Balance of Payments}

Note that due to Walras' law the balance of payments is implied by the budget constraints, labor market clearing conditions, and the zero-profit conditions. Let us start with the aggregate flow budget 
constraint in the poor country in the full-trade equilibrium

$$
\dot{A}_{P}(t)=r^{P}(t) A_{P}(t)+w^{P}(t) \beta L \theta_{P}-\beta L N(t) z_{P}(t)+\beta L T_{P}(t)
$$

If we choose the marginal cost of production for firms located in the poor country as numeraire, i.e. $w^{P}(t) b^{P}(t)=1$, we can write the flow budget constraint as follows

$$
\frac{\dot{N}^{P}(t)}{N^{P}(t)} \frac{F^{P}}{b^{P}}=r^{P}(t) \frac{F^{P}}{b^{P}}+\frac{N(t)}{N^{P}(t)} \frac{\beta L \theta_{P}}{b^{P}}-\beta L \frac{N(t)}{N^{P}(t)} z_{P}(t)+\frac{N(t)}{N^{P}(t)} \frac{\beta L T_{P}(t)}{N(t)}
$$

where capital market clearing in country $P$ implies that $A_{P}(t)=N^{P}(t) F^{P} / b^{P}$. Next, the labor market clearing condition in the poor country is determined by (3.6) and can be written as

$$
\frac{\dot{N}^{P}(t)}{N^{P}(t)} \frac{F^{P}}{b^{P}}=\frac{N(t)}{N^{P}(t)} \frac{\beta L \theta_{P}}{b^{P}}-\beta L-\tau(1-\beta) L
$$

We can rewrite the zero-profit condition in the poor country as

$$
r^{P}(t) \frac{F^{P}}{b^{P}}=\left[z_{P}(t)-1\right] \beta L+\left[z_{R}(t)-\tau\right](1-\beta) L
$$

Substituting the labor market clearing and the zero-profit condition into the flow budget constraint yields the balance of payments

$$
\begin{aligned}
\frac{\beta L \theta_{P}}{\zeta(t) b^{P}}-\beta L-\tau(1-\beta) L & =\left[z_{P}(t)-1\right] \beta L+\left[z_{R}(t)-\tau\right](1-\beta) L+\frac{\beta L \theta_{P}}{\zeta(t) b^{P}}-\frac{\beta L z_{P}}{\zeta(t)}+\frac{1}{\zeta(t)} \frac{\beta L T_{P}(t)}{N(t)} \\
{[1-\zeta(t)] \beta L z_{P}(t) } & =\zeta(t)(1-\beta) L z_{R}(t)+\beta L \frac{T_{P}(t)}{N(t)} \\
N^{R}(t) \beta L z_{P}(t) & =N^{P}(t)(1-\beta) L z_{R}(t)+\beta L T_{P}(t)
\end{aligned}
$$

where $\zeta(t) \equiv N^{P}(t) / N(t)$. Note that alternatively we could have derived the balance of payments from the aggregate flow budget constraint, the labor market clearing condition, and the zero-profit condition in the rich country. 


\subsubsection{Steady state}

The following equations determine the full-trade steady state

$$
\begin{aligned}
g & =r-\rho \\
(1-\beta) L \theta_{R} & =g(1-\zeta) F^{R}+(1-\zeta) b^{R}(1-\beta) L+(1-\zeta) \tau b^{R} \beta L \\
\beta L \theta_{P} & =g \zeta F^{P}+\zeta b^{P} \beta L+\zeta \tau b^{P}(1-\beta) L \\
\omega^{R} F^{R} & =\frac{\left(z_{R}-\omega^{R} b^{R}\right)(1-\beta) L+\left(z_{P}-\tau \omega^{R} b^{R}\right) \beta L}{r} \\
\frac{F^{P}}{b^{P}} & =\frac{\left(z_{P}-1\right) \beta L+\left(z_{R}-\tau\right)(1-\beta) L}{r} \\
(1-\zeta) \beta L z_{P} & =\zeta(1-\beta) L z_{R}+\beta L T
\end{aligned}
$$

where $\omega^{R} \equiv w^{R}(t) / N(t)$ and $T \equiv T_{P}(t) / N(t)$.

\subsubsection{Prices and relative wages in steady state}

We can solve for prices $z_{R}$ and $z_{P}$ as functions of the endogenous variables $g$ and $\zeta$ as follows

$$
\begin{aligned}
& z_{R}=\frac{1-\zeta}{1-\beta}\left\{\frac{F^{P}}{b^{P} L}(g+\rho)+[\beta+\tau(1-\beta)]\right\}-\frac{\beta}{1-\beta} T \\
& z_{P}=\frac{\zeta}{\beta}\left\{\frac{F^{P}}{b^{P} L}(g+\rho)+[\beta+\tau(1-\beta)]\right\}+T
\end{aligned}
$$

We see that there is a positive relationship between prices (or the willingness to pay) and the growth rate $g$ for a given production share of the poor country $\zeta$. Furthermore, the relationship between $z_{R}$, respectively, $z_{P}$, and $\zeta$ is ceteris paribus negative, respectively, positive. For the case of identical technologies across countries, i.e. $F^{R}=F^{P}=F$ and $b^{R}=b^{P}=b$, we can formulate the following proposition

Proposition 5. The larger country has ceteris paribus the higher wage rate.

Proof. In general, we can write the (relative) wage rate $\omega^{R}$ in the rich country as follows

$$
\omega^{R} b^{R}=\frac{\frac{F^{P}}{b^{P}}\left[(1-\beta) z_{R}+\beta z_{P}\right]}{\frac{F^{R}}{b^{R}}\left[(1-\beta) z_{R}+\beta z_{P}\right]+\frac{F^{P}}{b^{P}}[(1-\beta)+\tau \beta]-\frac{F^{R}}{b^{R}}[\beta+\tau(1-\beta)]}
$$

Imposing symmetric technologies across countries, we can write

$$
\omega^{R} b=\frac{\left[(1-\beta) z_{R}+\beta z_{P}\right]}{\left[(1-\beta) z_{R}+\beta z_{P}\right]+(1-\tau)(1-2 \beta)}
$$

It is straightforward to see that if technologies and population sizes are identical, i.e. $\beta=1 / 2$, across 
countries wage rates equalize, i.e. $\omega^{R} b=1$ (remember our choice of numeraire $\omega^{P} b=1$ ). If $\beta<1 / 2$ the second term in the denominator is positive (remember that $\tau>1$ ) so that the numerator is larger than the denominator, and therefore $\omega^{R} b^{R}>1$. In other words, as in the standard model with CES preferences the larger country has the higher wage rate as a result of the home market effect (if $\tau=1$ there is no home market effect, and we see that wages equalize across countries).

\subsection{Part-trade equilibrium}

\subsubsection{Steady state}

The following equations determine the part-trade steady state

$$
\begin{aligned}
g & =r-\rho \\
(1-\beta) L \theta_{R} & =g(1-\zeta) F^{R}+(1-\zeta) b^{R}(1-\beta) L+\Omega(1-\zeta) \tau b^{R} \beta L \\
\beta L \theta_{P} & =g \zeta F^{P}+\zeta b^{P} \beta L+\zeta \tau b^{P}(1-\beta) L \\
\left(z_{R}-\omega^{R} b^{R}\right)(1-\beta) L & =\left(\tau z_{P}-\omega^{R} b^{R}\right)(1-\beta) L+\left(z_{P}-\tau \omega^{R} b^{R}\right) \beta L \\
\omega^{R} F^{R} & =\frac{\left(z_{R}-\omega^{R} b^{R}\right)(1-\beta) L}{r} \\
\frac{F^{P}}{b^{P}} & =\frac{\left(z_{P}-1\right) \beta L+\left(\tau z_{P}-\tau\right)(1-\beta) L}{r} \\
\beta L \Omega(1-\zeta) z_{P} & =(1-\beta) L \zeta \tau z_{P}+\beta L T
\end{aligned}
$$

where $\omega^{R} \equiv w^{R}(t) / N(t)$ and $T \equiv T_{P}(t) / N(t)$.

\subsubsection{Prices and relative wages in steady state}

We can solve for prices as a function of the endogenous variable $g$ as follows

$$
\begin{aligned}
& z_{R}=\left[1+\frac{g+\rho}{(1-\beta) L}\right] \omega^{R} b^{R} \\
& z_{P}=1+\frac{F^{P}}{b^{P} L} \frac{g+\rho}{[\beta+\tau(1-\beta)]}
\end{aligned}
$$

where the wage rate $\omega^{R} b^{R}$ is determined below. As in the full-trade steady state, if technologies are identical across countries, we propose that

Proposition 6. The larger country has the higher wage rate, holding everything else constant.

Proof. In general, we can write the (relative) wage rate $\omega^{R}$ as follows

$$
\omega^{R} b^{R}=\frac{\frac{F^{P}}{b^{P}}(g+\rho)+[\beta+\tau(1-\beta)] L}{\frac{F^{R}}{b^{R}}(g+\rho)+[(1-\beta)+\tau \beta] L}
$$


Imposing symmetric technologies across countries implies that

$$
\omega^{R} b=\frac{\frac{F}{b}(g+\rho)+[\beta+\tau(1-\beta)] L}{\frac{F}{b}(g+\rho)+[(1-\beta)+\tau \beta] L}
$$

It is easy to see that if population sizes are identical in both countries, i.e. $\beta=1 / 2$, wage rates equalize, i.e. $\omega^{R} b=1$ (due to our choice of numeraire). If $\beta<1 / 2$ it is straightforward to show that $\omega^{R} b>1$, and vice versa for $\beta>1 / 2$. This is identical to the full-trade equilibrium.

\subsubsection{Inequality simulations}

To simulate the effects of a change in between-country income inequality we choose the following parameter values $L=1, \beta=0.5, \theta_{R}=2.1, \theta_{P}=1.9, F^{R}=F^{P}=7, b^{R}=b^{P}=1, \rho=0.05$, and $\tau=1.6$. This parameter configuration supports a full-trade equilibrium with $g=0.1, \zeta=0.475, n=1, w=1$, $p=1.1053$ and $G=0.025$, where $n \equiv \Omega(1-\zeta)+\zeta$ denotes the consumption of a household in the poor relative to the rich country, $w \equiv w^{R}(t) / w^{P}(t)$ the relative wage rate, $p \equiv z_{R} / z_{P}$ the terms of trade (for the poor country) and $G$ the Gini coefficient. Note that since technologies and population sizes are identical across countries wage rates equalize. We assume identical technology and population size across countries to isolate the effects of inequality.
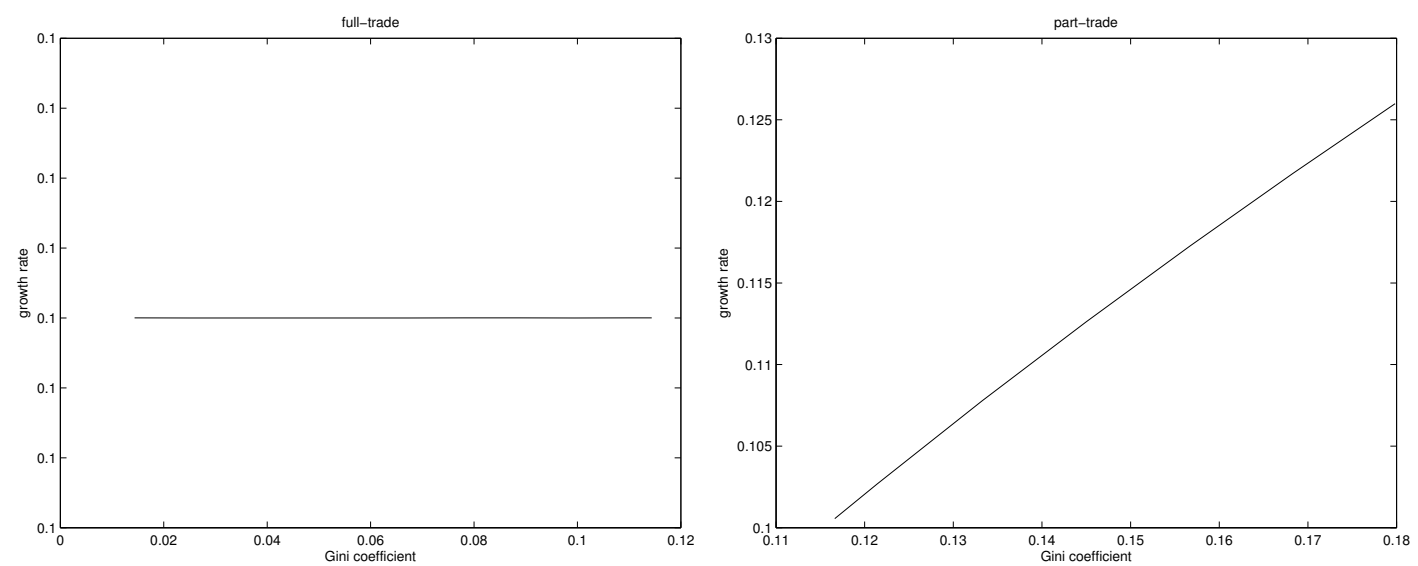

Figure 6: Effect of inequality on growth rate in full-trade equilibrium (left-hand side) and in part-trade equilibrium (right-hand side) 

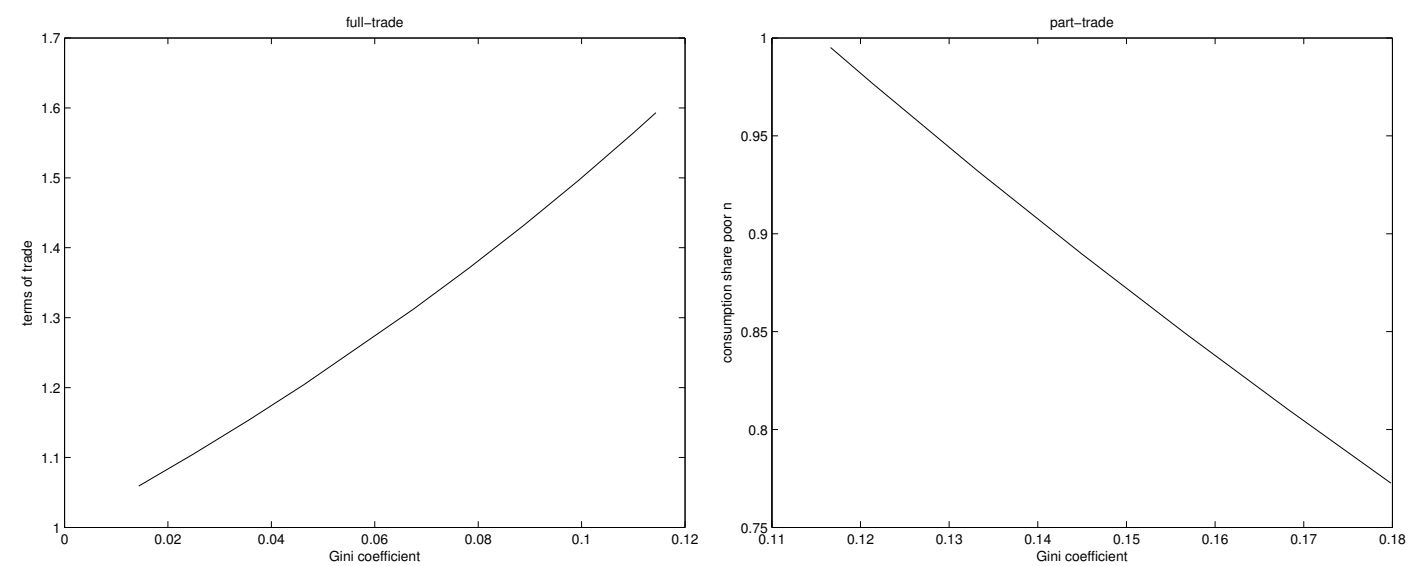

Figure 7: Effect of inequality on terms of trade in full-trade equilibrium (left-hand side), and on relative consumption poor to rich $n$ in part-trade equilibrium (right-hand side)
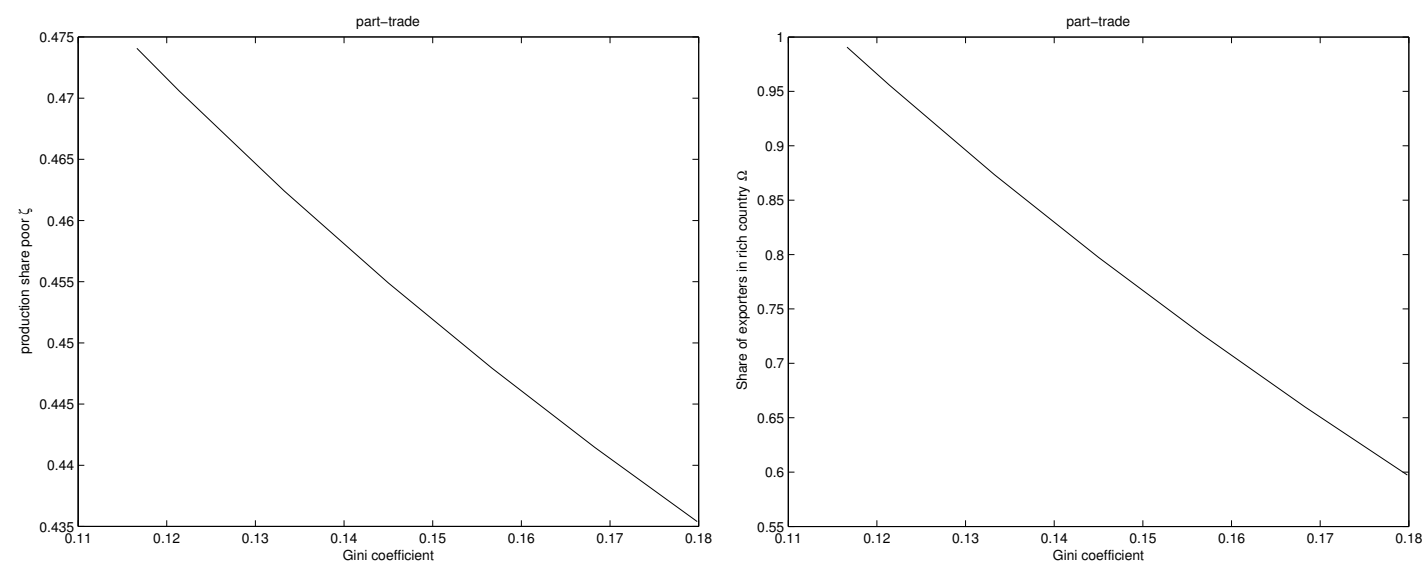

Figure 8: Effect of inequality on production share $\zeta$ in part-trade equilibrium (left-hand side), and on the share of exporting firms $\Omega$ in part-trade equilibrium (right-hand side)

\subsubsection{Technology simulations}

We simulate an increase in relative labor productivity in $R \& D$ in the poor country by choosing the following parameter values $L=1, \beta=0.5, \theta_{R}=2.1, \theta_{P}=1.9, F^{R}=10, F^{P}=100, b^{R}=1, b^{P}=1$, $\rho=0.05, \tau=1.6$, and $T=0$. This parameter configuration supports a part-trade equilibrium with $g=0.0510, \zeta=0.1485, n=0.3860, w=4.9348$, and $G=0.3251$, where $n \equiv \Omega(1-\zeta)+\zeta$ denotes the consumption of a household in the poor relative to the rich country, $w \equiv w^{R}(t) / w^{P}(t)$ the relative wage rate, and $G$ the Gini coefficient. Note that technologies are no longer identical across countries so that wage rates are not equalized. 

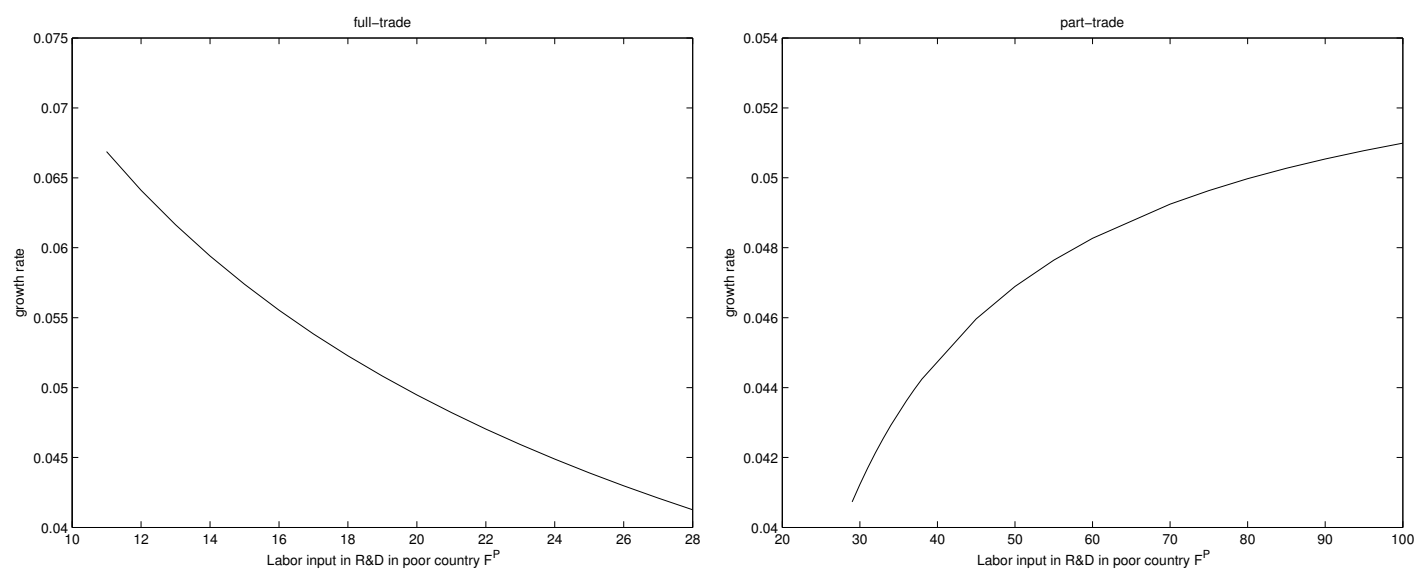

Figure 9: Effect of labor productivity in $\mathrm{R} \& \mathrm{D}$ on growth rate in full-trade equilibrium (left-hand side) and in part-trade equilibrium (right-hand side)
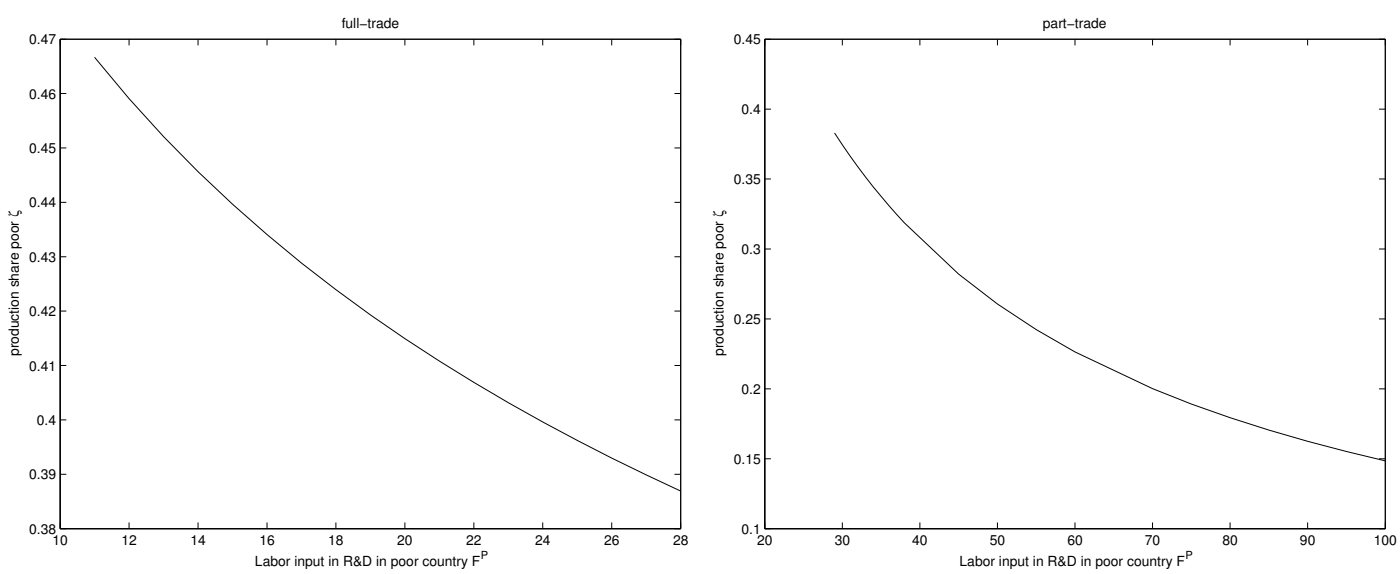

Figure 10: Effect of labor productivity in $R \& D$ on production share of poor country in full-trade equilibrium (left-hand side) and in part-trade equilibrium (right-hand side)
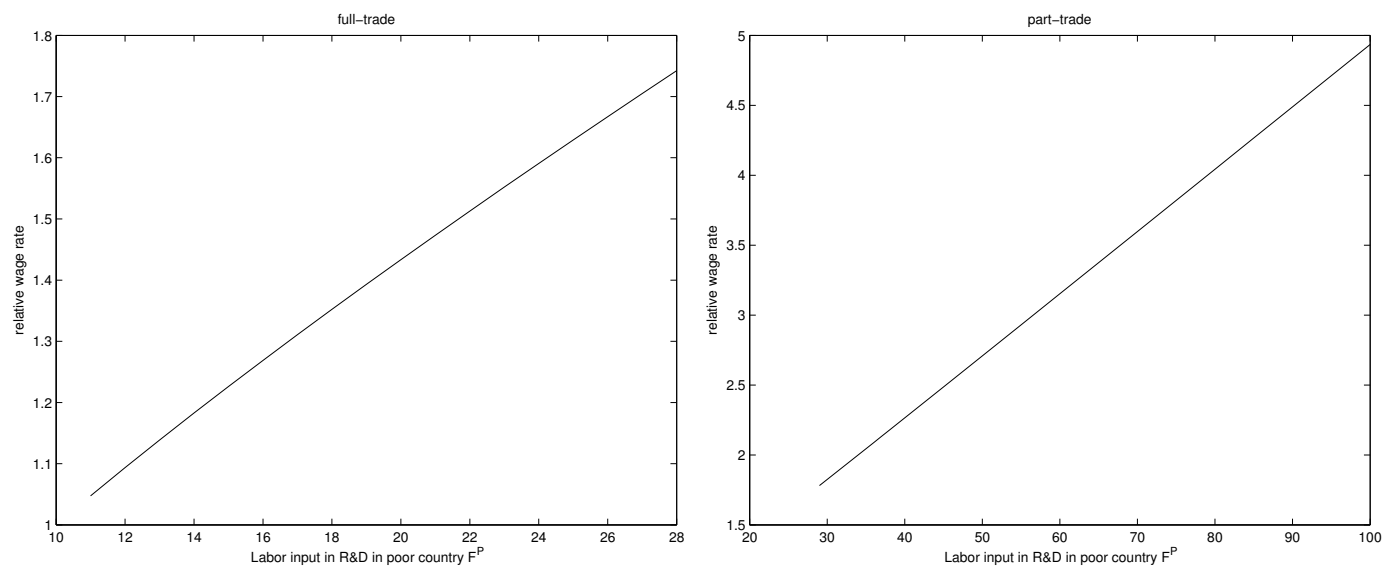

Figure 11: Effect of labor productivity in $R \& D$ on relative wages in full-trade equilibrium (left-hand side) and in part-trade equilibrium (right-hand side) 


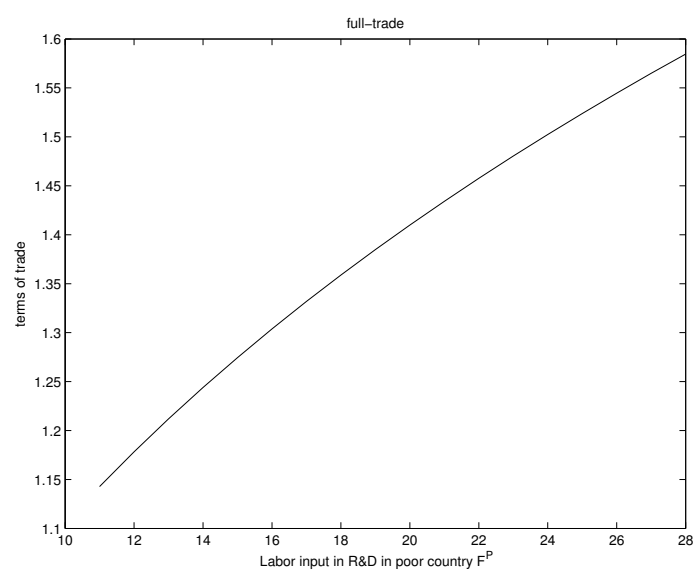

Figure 12: Effect of labor productivity in R\&D on terms of trade in full-trade equilibrium

\subsection{Transition}

It is straightforward to solve the system of linear differential equations given in the text (see for example Acemoglu, 2009). We write the system in matrix form and define the $2 \times 2$ matrix $Q$ as follows (for ease of notation we drop the subscript $k$ )

$$
Q \equiv\left[\begin{array}{cc}
\Phi^{R} & \Psi^{R} \\
\Psi^{P} & \Phi^{P}
\end{array}\right]
$$

Note that the constants $\Phi_{k}^{R}, \Psi_{k}^{R}, \Phi_{k}^{P}$ and $\Psi_{k}^{P}$ are defined as follows. In the full-trade equilibrium, we have $\Phi_{\text {full }}^{R} \equiv\left[(1-\beta) L \theta_{R}-[(1-\beta)+\tau \beta] b^{R} L\right] / F^{R}, \Psi_{\text {full }}^{R} \equiv(1-\beta) L \theta_{R} / F^{R}>0, \Phi_{\text {full }}^{P} \equiv$ $\left[\beta L \theta_{P}-[\beta+\tau(1-\beta)] b^{P} L\right] / F^{P}$, and $\Psi_{\text {full }}^{P} \equiv \beta L \theta_{P} / F^{P}>0$. Whereas in the part-trade equilibrium, we have $\Phi_{\text {part }}^{R} \equiv(1-\beta) L\left(\theta_{R}-b^{R}\right) / F^{R}>0, \Psi_{\text {part }}^{R} \equiv(1-\beta) L\left(\theta_{R}-\tau^{2} b^{R}\right) / F^{R}>0$, $\Phi_{\text {part }}^{P} \equiv\left[\beta L \theta_{P}-[\beta+\tau(1-\beta)] b^{P} L\right] / F^{P}$, and $\Psi_{\text {part }}^{P} \equiv \beta L \theta_{P} / F^{P}>0$, where $\Phi_{\text {part }}^{R}>0$ and $\Psi_{\text {part }}^{R}>0$ follows from Proposition 4.

The matrix $Q$ can be decomposed as follows, $Q=P \mu P^{-1}$, where $P$ is a matrix whose columns correspond to the eigenvectors of $Q$ and $\mu$ is a diagonal matrix with the eigenvalues of $Q$ on its diagonal. By the definition of an eigenvalue, $\operatorname{det}(Q-\mu I)=0$, the eigenvalues of $Q$ are determined by the following quadratic equation

$$
\mu^{2}-\left(\Phi^{R}+\Phi^{P}\right) \mu+\left(\Phi^{R} \Phi^{P}-\Psi^{R} \Psi^{P}\right)=0
$$


with the solutions given by

$$
\mu_{1,2}=\frac{\left(\Phi^{R}+\Phi^{P}\right) \pm \sqrt{\left(\Phi^{R}+\Phi^{P}\right)^{2}-4\left(\Phi^{R} \Phi^{P}-\Psi^{R} \Psi^{P}\right)}}{2}
$$

By the definition of an eigenvector, $\left(Q-\mu_{1} I\right) v^{1}=0$, the eigenvector $v^{1}$ associated with the eigenvalue $\mu_{1}$ is determined by following system of linearly dependent equations

$$
\left[\begin{array}{c}
\left(\Phi^{R}-\mu_{1}\right) v_{1}^{1}+\Psi^{R} v_{2}^{1} \\
\Psi^{P} v_{1}^{1}+\left(\Phi^{P}-\mu_{1}\right) v_{2}^{1}
\end{array}\right]=\left[\begin{array}{l}
0 \\
0
\end{array}\right]
$$

By normalizing $v_{2}^{1}=1$, respectively, $v_{2}^{2}=1$, it follows that the eigenvector $v^{1}$, respectively $v^{2}$, is given by

$$
v^{1}=\left[\begin{array}{c}
\frac{\mu_{1}-\Phi^{P}}{\Psi^{P}} \\
1
\end{array}\right], \quad v^{2}=\left[\begin{array}{c}
\frac{\mu_{2}-\Phi^{P}}{\Psi^{P}} \\
1
\end{array}\right]
$$

Hence, the matrices $P$ and $\mu$ are

$$
P=\left[\begin{array}{cc}
v_{1}^{1} & v_{1}^{2} \\
v_{2}^{1} & v_{2}^{2}
\end{array}\right]=\left[\begin{array}{cc}
v_{1}^{1} & v_{1}^{2} \\
1 & 1
\end{array}\right], \quad \mu=\left[\begin{array}{cc}
\mu_{1} & 0 \\
0 & \mu_{2}
\end{array}\right]
$$

The system of equations is decoupled by canonical variables decomposition. The decoupled (transformed) system is easily solved, and retransformed. The solution is then given by

$$
\left[\begin{array}{c}
N^{R}(t) \\
N^{P}(t)
\end{array}\right]=\left[\begin{array}{c}
v_{1}^{1} c_{1} \exp \left(\mu_{1} t\right)+v_{1}^{2} c_{2} \exp \left(\mu_{2} t\right) \\
c_{1} \exp \left(\mu_{1} t\right)+c_{2} \exp \left(\mu_{2} t\right)
\end{array}\right]
$$

with the constants of integration, $c_{1}$ and $c_{2}$ determined by

$$
c_{1}=\frac{N^{P}(0) v_{1}^{2}-N^{R}(0)}{v_{1}^{2}-v_{1}^{1}}, \quad c_{2}=\frac{N^{R}(0)-N^{P}(0) v_{1}^{1}}{v_{1}^{2}-v_{1}^{1}}
$$

where $N^{R}(0)>0$ and $N^{P}(0)>0$ are given. From this solution the dynamics of all other variables can be obtained. 